\title{
The Effect of Boric Acid and Borax on the Broad Bean and certain other Plants. ${ }^{1}$
}

\author{
BY
}

KATHERINE WARINGTON, M.SC.

(Rothamsted Experimental Station.)

With Plate XIII and six Figures in the Text.

\section{Contents.}

I. INTRODUCTION

II. Experimental Work .

I. Water Cultures

A. Broad Beans

a. The effect of different concentrations of boric acid in the nutrient solution

(a) Development of the root

(b) Development of the shoot

(c) Discussion of dry weights

(d) $\frac{\text { Shoot }}{\text { Koot }}$ ratio

$\beta$. The effect of adding boric acid at different stages of growth . . . . . 638

(a) General type of recovery subsequent to the addition of boric acid . . . 639

(b) Effect of the concentration of boric acid supplied . . . . . . 640

$\gamma$. The effect of removing boric acid at different stages of growth . . . . . $64 \mathrm{I}$

a) Death subsequent to the removal of boric acid . . . . . . $64^{2}$

(b) Effect of the concentration of boric acid supplied . . . . . . 642

$\delta$ The effect of the removal of the cotyledons on subsequent growth in water culture . 644

B. Barley . • • • • • • • • • • • • • . 645

a. The effect of different concentrations of boric acid in the nutrient solution . . 646

(a) Development of the root . . . . . . . . . 646

(b) Development of the shoot . . . . . . . . . . . 646

$\beta$. Comparison between the effect of boric acid and borax in the nutrient solution, with discussion of dry weights in $a$ and $\beta$. . . . . . . . 647

$\gamma$. Comparison between the effect of boric acid on broad beans and barley . . 650

C. Miscellaneous Plants . • . . . . . . . . . . 650

(a) Phaseolus multiforus . . . . . . . . . . . . 650

(b) Phaseolus vulgaris. . . . . . . . . . . . . 65I

(c) Trifolium incarnatum . . . . . . . . . . . . $66_{5}$

(d) Trifolium repens . • . • • • • • • • • • $66_{52}$

1 Thesis approved for the M.Sc. Degree, London University.

[Annals of Botany, Vol. XXVII. No. CXLVIII. October, 1923.] 
2. Pot Cultures .

(e) Pisum sativum, (I) Harbinger, (2) Pioneer

(f) Winter Vetch

$(g)$ Rye

A. Broad Beans

a. The effect of adding various quantities of boric acid to the soil .

(a) Boric acid mixed throughout the soil

(b) Boric acid supplied as a top-dressing

$\beta$. Comparison between the effect of boric acid and borax in the soil

$\gamma$. Comparison between the application of boric acid at two different stages of growth:

B. Barley

(I) At the time of sowing, (2) Seventeen days later . . . . . . 657

a. The effect of adding various quantities of boric acid to the soil . . . . 658

(a) Boric acid mixed throughout the soil . . . . . . . . 658

(b) Boric acid applied as a top-dressing fifteen days after sowing . . . . 660

B. Comparison between the effect of boric acid and borax in the soil . . . . 66 I

3. Field Experiments .

A. Broad Beans

B. Barley

iII. General Discussion and Summary

IV. BIBLIOGKAPHY

\section{INTRODUCTION.}

$\mathrm{T}$ HE action on plant life of chemical elements, other than those usually considered nutritive, is of such fundamental importance that a large volume of work has been done on the subject. Many of these substances have been found to occur naturally in plant tissues, boron being first discovered by Wittstein and Apoiger (37) in 1857 , and since that date many investigations have been made on the distribution of boron compounds and their influence on plant life.

Bertrand $(4(b))$ has made a wide study of these plant poisons, including boric acid, and has drawn special attention to their beneficial effect when presented in very small quantities: Pellet (29), however, holds that no favourable action results from the use of manganese, aluminium, or boron compounds in the cultivation of sugar beet; but Agulhon's work with boron compounds is of particular interest, on account of his exhaustive treatment of the subject, and the large variety of plants studied. Most of the other important work prior to 19I4 has been dealt with by Brenchley $(11(b))$.

More recent investigations have been chiefly American, dealing mainly with the toxic effect of boron compounds present in fertilizers used in the field. Experiments of this type have been carried out by Conner and Fergus $(14,15)$, Schreiner and his collaborators (33), Plummer and Wolff (30), Proulx and others (31), Brown (12), Blair (6), and Blackwell and Collins (8).

The results of these large-scale experiments show clearly the complexity 
of the subject, since the reaction of the plant is seen to depend on the crop, the nature of the soil, the type of boron compound and the method of its application. In addition, the rainfall and other seasonal conditions are of the greatest importance. Though the injurious effect of boron on plants has been emphasized by the American work, cases of possible stimulation are mentioned. However, there is nothing comparable to the extraordinary beneficial results obtained by the earlier French work of Bertrand $(4 \cdot(b))$ and Agulhon $(1(a))$; recently Bruno (13) has put forward a criticism of the methods employed in the U.S.A. as a possible explanation of the inconsistent results obtained in the two countries. But since so little is at present known about the part played by such substances as boron compounds in the plant, and further the reaction of the plant is dependent on so many external factors, it is hardly surprising that all experimental results should not fall into line.

In some experiments carried out by Dr. J. Davidson at Rothamsted in 1920 in connexion with the bean aphis, broad bean plants in water-culture solution supplied with a small quantity of boric acid were strikingly superior to the rest of the series. Accordingly, the present investigation was undertaken in order to determine more fully the action of boric acid on the broad bean and certain other plants.

\section{ExPerimental Work.}

The methods employed were as follows:

(I) Water culture.

(2) Pot culture.

(3) Field experiments.

\section{Water Cultures.}

Experiments were carried out chiefly with broad beans and barley.

Germination was effected in damp sawdust, the seedlings being placed in their respective solutions when they had developed roots of $I$ to $2 \mathrm{in}$. in length, usually about ten days after sowing.

The Rothamsted food solution, with composition as follows, was used in every case :

$$
\left\{\begin{array}{l}
\mathrm{KNO}_{3} \quad \text { I grm. } \\
\mathrm{KH}_{2} \mathrm{PO}_{4} 0.5 " \\
\mathrm{NaCl} \quad 0.5 " \\
\mathrm{CaSO}_{4} \quad 0.5 " \\
\mathrm{MgSO}_{4} 0.5 " \\
\mathrm{FeCl}_{3} 0.04 \text { grm. } \\
\text { Distilled water to make up I litre. }
\end{array}\right.
$$

This solution was tested for the presence of boron, but the result was negative. 
The nutrient solutions were renewed frequently. Three weeks usually elapsed before the first change, but later fresh solution was supplied at fortnightly or weekly intervals. The bottles were kept well filled with distilled water between the renewing of the solutions. Sufficient aeration of the roots seemed to be effected by this means. The plants were grown in separate bottles, each of 600 c.c. capacity.

\section{A. Broad Beans.}

The variety of broad bean used throughout this work was Sutton's Prolific Longpod, and the seed was graded by weight for each experiment.

\section{a. The Effect of Different Concentrations of Boric Acid in the Nutrient} Solution.

In the first three series the effect of a wide range of concentrations of $\mathrm{H}_{3} \mathrm{BO}_{3}$ was tried, viz. from $\mathrm{I}: 5,000$ to $\mathrm{I}: 100,000,000$.

Five or ten plants were taken as the unit.

The experiments were carried out at three different seasons of the year, spring, early summer, and autumn respectively. Consequently, the plants were grown under totally different conditions of light, temperature, and humidity. However, in spite of this, and the corresponding variation in such vital plant processes as transpiration, carbon assimilation, and respiration, the main results in all three cases were consistent, showing that seasonal changes cannot in any way be responsible for the remarkable effects attributed to the action of boric acid.

(a) Development of the root. Differences between the plants were first evident in the root system, being noticeable after only five to seven days' growth in their respective solutions.

$$
\mathrm{H}_{3} \mathrm{BO}_{3} \mathrm{I}: 5: 000 \text {. }
$$

The root development was poor, but on the whole better than that of the controls, though in a comparison of their dry weights little difference was seen (Table I). The first-formed laterals also showed a strong tendency to arise in the upper portion of the primary root, above the solution, and to grow out at a wide angle as if trying to avoid entering the liquid (Text-fig. I). Later the rootlets were more evenly distributed and altogether appeared quite normal. A few isolated cases of curled root-tips were noticed, but it was uncertain whether this was due to the poisonous nature of the solution or to some mechanical factor.

$$
\mathrm{H}_{3} \mathrm{BO}_{3} \mathrm{I}: 25,000 \text { and } \mathrm{I}: 50,000 \text {. }
$$

These two sets showed up very strikingly after a week's growth. The laterals were more numerous than in any other set, and there was only a slight tendency shown for them to be at first localized in the upper portion. 
of the root (Text-fig. I). Of the two, the $1: 25,000$ set more nearly resembled the $\mathrm{I}: 5,000$, while in the plants grown with $\mathrm{I}: 50,000 \mathrm{H}_{3} \mathrm{BO}_{3}$ but few of the characteristics of the roots grown in the strongest solution were evident; thus it would seem that the high concentration of the boric acid was the factor responsible for any peculiarities in growth in the latter solution.

$$
\mathrm{H}_{3} \mathrm{BO}_{3} \mathrm{I}: \mathrm{I00}, 000, \mathrm{I}: 500000 \text {, and } \mathrm{I}: 2,500,000 \text {. }
$$

The roots of the plants in these concentrations were slower in developing than those receiving a somewhat larger quantity. None of the character-

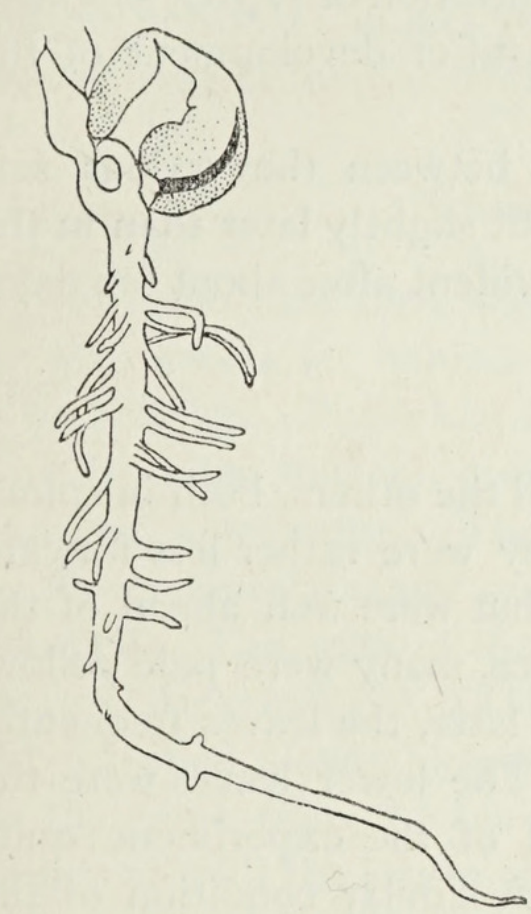

1:5,000 Boric Acid

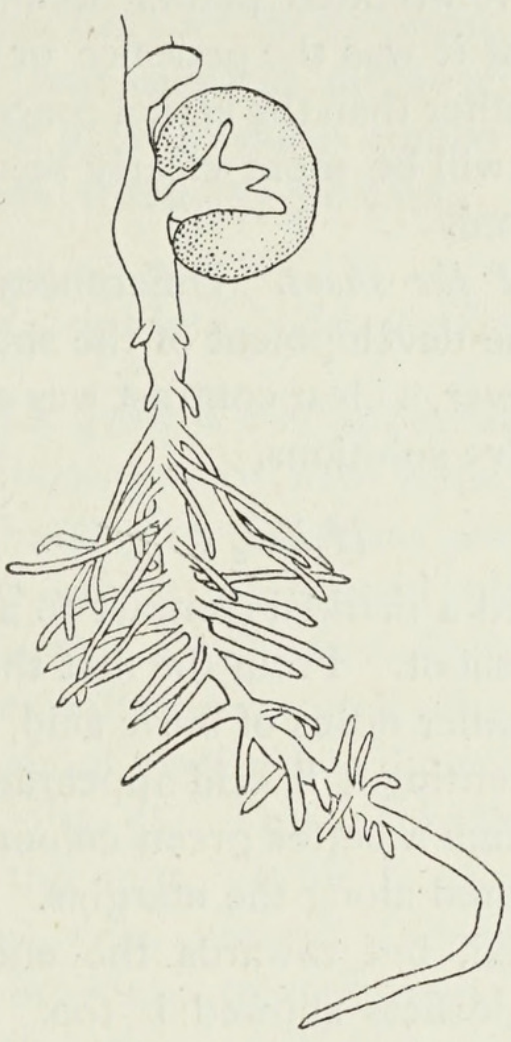

1:50,000 Boric Acid

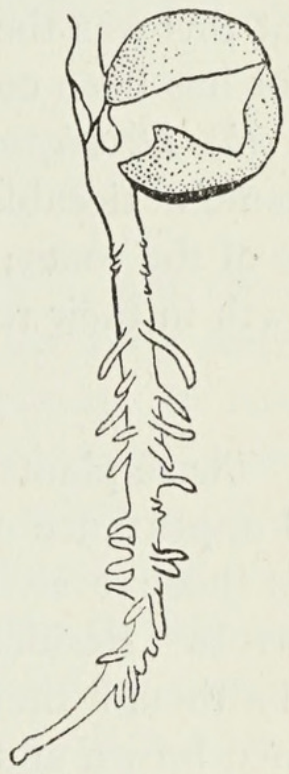

No Boric Acid

TEXT-FIG. I. Typical broad bean seedlings after five days' growth in a nutrient solution with or without boric acid.

istics of the $I: 5,000$ set were seen, but, on the other hand, growth was not so good as in the case of plants treated with $\mathrm{I}: 50,000 \mathrm{H}_{3} \mathrm{BO}_{3}$.

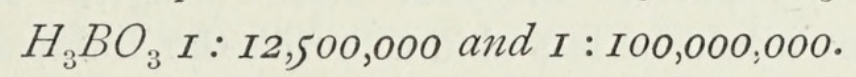

As might be expected, the plants in the most dilute solution of boric acid showed little difference in their root development from the untreated plants, but those in I : I 2,500,000 $\mathrm{H}_{3} \mathrm{BO}_{3}$ made decidedly more growth than either the $I: 100,000,000$ set or the controls, and the dry weight figures bear this out (Table I).

\section{Control: no Boric Acid supplied.}

At first the development of the root compared favourably with the other sets, but very soon fell behind (Text-fig. I). In the majority of cases the 
type of root was most distinctive, being short and thick with a stunted appearance ${ }^{1}$ (Pl. XIII, Fig. I). However, the individual variation was very great and a few isolated cases occurred with the long thin type of root, which was that universally met with among the plants supplied with boric acid (Pl. XIII, Fig. 2), but in no case was a good root system developed.

While the contrasts between the root development of the individual sets supplied with different concentrations of boric acid were much more strongly marked in the early stages of growth, the difference between the controls and all the boron-treated plants became more evident as growth went on, suggesting that it was the presence or absence of boron that was the important factor, rather than the actual concentration of $\mathrm{H}_{3} \mathrm{BO}_{3}$ supplied. That this was the case will be more clearly seen after development of the shoot has been considered.

(b) Development of the shoot. Differences between the various sets became noticeable in the development of the shoot slightly later than in the case of the roots; however, a clear contrast was evident after about ten days' growth in their respective solutions.

$$
\mathrm{H}_{3} \mathrm{BO}_{3} \mathrm{I}: 5,000 \text {. }
$$

These plants offered a marked contrast to all the others, both in colour and appearance of the shoot. From the first they were rather less forward than those receiving smaller doses of boric acid, but were well ahead of the controls. Besides presenting a flaccid appearance, many were pale yellow, and although they became a better green colour later, the leaves frequently turned brown and withered along the margins. The lower leaves were the first to become affected, but towards the end of the experiment quite a number of the upper leaflets showed it too. A similar condition of the leaf has been described by Brenchley $(11(a))$ for peas grown in high concentrations of boric acid. In the experiment carried out in the spring the plants were much more severely injured than those receiving exactly the same treatment during the summer months. This was probably due to the fact that both the rate of growth and the vitality of the plant would be less vigorous in the early part of the year than ciuring the summer, and consequently the plant would be less able to resist the influence of the poison. A similar relationship between the season and the degree of toxicity of a given amount of poison has been more fully described by Brenchley $(11(a))$ in the case of the action of both zinc sulphate and boric acid on peas and barley.

$$
\mathrm{H}_{3} \mathrm{BO}_{3} \mathrm{I}: 25,000, \mathrm{I}: 50,000 \text {, and } \mathrm{I}: \mathrm{I00}, 000 \text {. }
$$

These three sets soon ran ahead of all the others, and for some time were decidedly the tallest plants, though this distinction in height gradually disappeared towards the close of the experiment.

\footnotetext{
1 See note at end.
} 
Poisoning effects were not much seen, being usually confined to the lower leaves.

$$
\mathrm{H}_{3} \mathrm{BO}_{3} \mathrm{I}: 500,000, \mathrm{I}: 2,500,000 \text { and } \mathrm{I}: \mathrm{I2}, 500,000 \text {. }
$$

Good shoot development was obtained in all these concentrations of boric acid, though the rate of growth was rather slower than where a slightly larger quantity had been given.

$$
\mathrm{H}_{3} \mathrm{BO}_{3} \mathrm{I}: \mathrm{I00}, 000,000 \text {. }
$$

As was seen in the case of the root development, such a small quantity of boric acid failed to create any apparent difference between these plants and the controls : in fact their growth was so similar that this concentration was omitted in the last of these three experiments.

\section{Contro!: no Boric Acid supplied.}

For the first three weeks growth was apparently normal, and though the plants were far behind those treated with boric acid, yet they seemed to be healthy. But when the rest of the series were beginning to flower (usually after four or more weeks) the control plants presented a very abnormal appcarance. They were small, stunted, and dark green in colour; the flower buds in many cases withered and fell off, while only a few plants bloomed. The apex of the shoot also withered, and the stem at this point became blackened (Pl. XIII, Fig. 3 ). This blackening started at the apex and travelled slowly down the stem, visible to the eye as black streaks. At the same time the leaves were affected. Their texture was leathery compared with the leaves of the boron-treated plants, and in many cases had the appearance of being covered with small yellow dots. They also showed a strong tendency to fall off, the base of the petiole being cut off quite clean. Mason (22) has described a somewhat comparable phenomenon in Sea Island cotton, attributing the boll-shedding to a retardation in the rate of production of assimilates. Macroscopic examination oi the petiole showed that the tissue was blackened in a similar way to the stem. A microscopical investigation of the anatomical changes is now being mace and will be described in a later paper.

All the control plants did not show this withering at the same time, and at the conclusion of one experiment several untreated plants remained apparently healthy, though this was unusual. Two such exceptional plants were allowed to continue growth for several weeks; three plants of similar age, but which had been continuously supplied with boric acid, were also kept on under the same conditions. At the end of a few weeks the untreated plants showed the typical 'dying off', while those receiving boric acid showed not the slightest indication of it, even after four months' growth, though by this time they had begun to die normally, the lower leaves 
turning yellow and falling off, death proceeding from below upwards. It would seem, therefore, that the period when the withering appears varies with the individual plant, but given sufficient time the 'dying off' phenomenon inevitably occurs.

The contrast between the shoots of plants treated with different concentrations of boric acid (except in extreme cases) was hardly evident

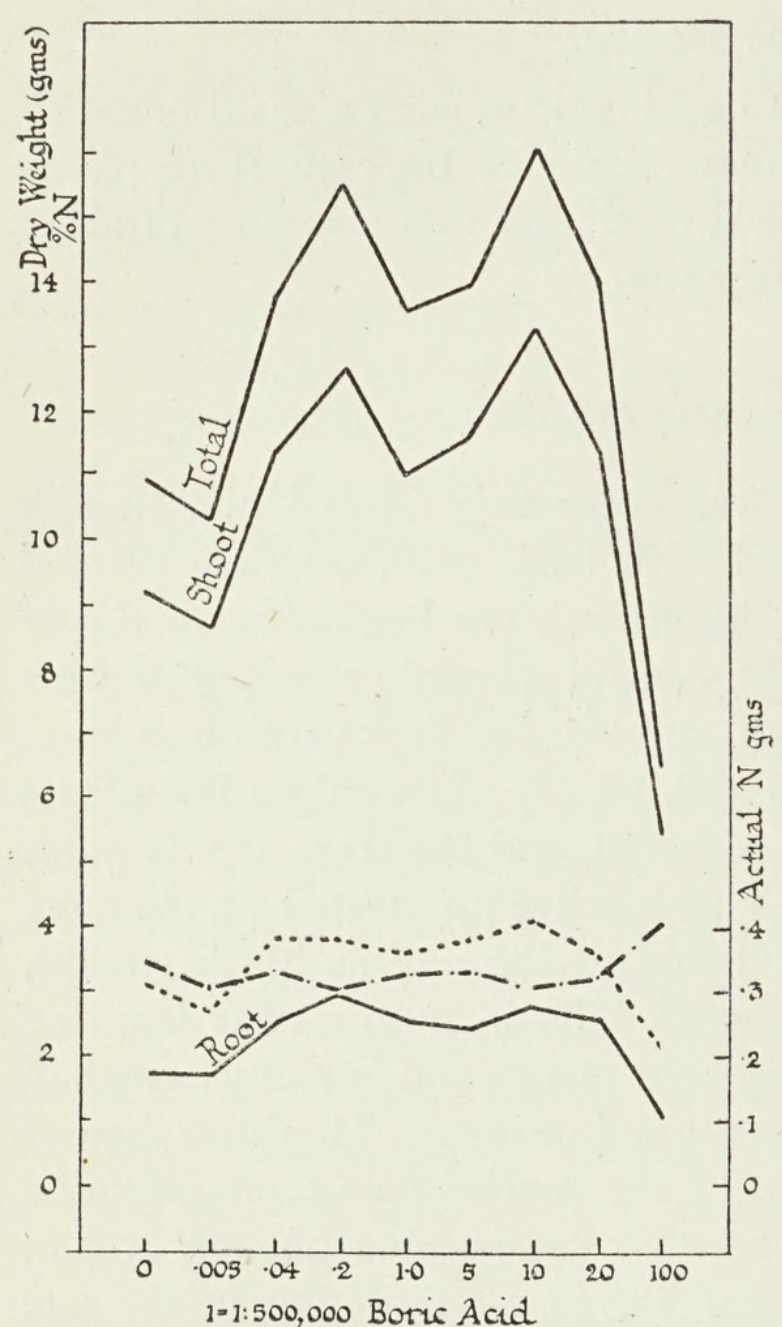

TexT-FIG. 2. Broad beans grown in water culture solution containing different quantities of boric acid. March Io-May I7, Iy2i (average of five plants): — Dry Weight; - - - - - per cent. Nitrogen ; -...... Actual N. towards the close of the experiment, while the difference in the growth of the controls from all the others was more clearly emphasized (Pl. XIII, Fig. 5). This gave support to the idea that the presence of boric acid was of fundamental importance, though the actual concentration within certain limits, approximately I $: 25,000-1:$ I 2,500,000, was of little consequence.

(c) Discussion of dry weights. The dry weight figures for these first three experiments on broad beans substantially support the conclusions which have already been drawn by inspection of the plants.

Consideration of Table I and Text-fig. 2 shows clearly that such a minute quantity of boric acid as I : 100,000,000 does not exert any appreciable influence on growth, but from $I: 12,500,000$ up to I $: 25,000$ a considerable increase over the figures for the control plants is seen. Above $I: 25,000$ a toxic effect is apparent in the case of the preliminary experiment carried out in the spring, though in the two remaining series the same quantity of boric acid appears to have been beneficial. This varying effect of a similar amount of the poison has already been shown to be dependent on seasonal conditions.

It is evident that though on the whole the addition of I : 50,000 boric acid yielded the best results, such widely varying quantities as I : $12,500,000$ or $I: 25,000$ were able to exert a beneficial effect of much the same order.

(d) $\frac{\text { Shoot }}{\text { Root }}$ ratio. A decided drop in the $\frac{\text { shoot }}{\text { root }}$ ratio below that of the 


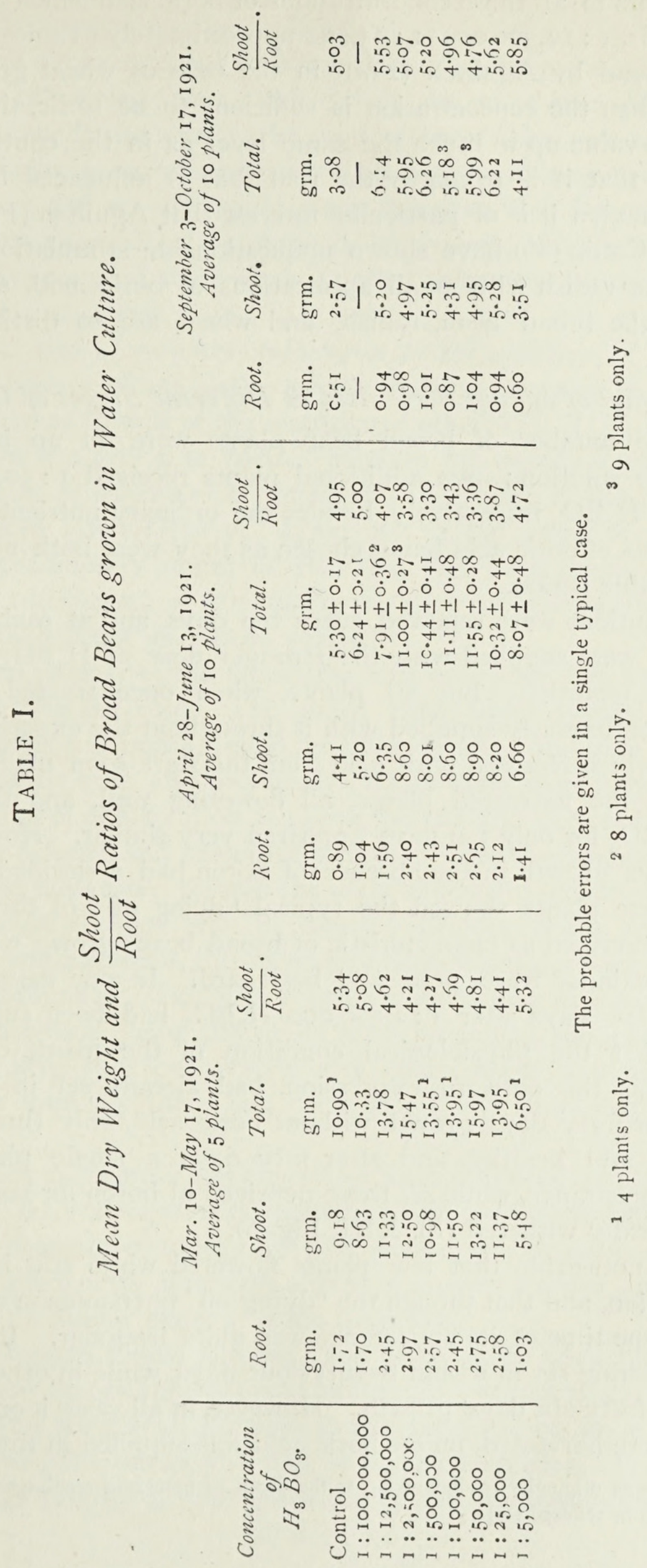




\section{Warington. - The Effect of Boric Acid and Borax on}

controls occurs in all those concentrations of boric acid which are favourable to growth, viz. I : I 2,500,000-I : 25,000 approximately (Table I). A similar drop was found by Agulhon $(1(\alpha))$ in the case of wheat grown in water culture. When the concentration is sufficient to be toxic, the ratio rises, bringing the value up to much the same level as in the controls. Thus it would seem that it is primarily the root that is influenced by boric acid. In this connexion it is of particular interest that Agulhon $(1(\alpha))$ and later Vinson and Catlin (35) have shown unquestionable stimulation of the root system of the radish with small applications of boric acid, since the root systems of the broad bean, radish, and wheat are so distinct from one another.

\section{The Effect of adding Boric Acid at Different Stages of Growth.}

A large number of broad bean plants were set up in the normal water-culture solution; five additional plants received I : 50,000 and five I : 2,500,00 $\mathrm{H}_{3} \mathrm{BO}_{3}$ respectively, besides the ordinary nutrient salts; these concentrations of boric acid being chosen as they were both near the limits of its favourable action.

The solutions were renewed every ten days, and at each change five ${ }^{1}$ more plants were supplied with the stronger dose of $\mathrm{H}_{3} \mathrm{BO}_{3}$ and five with the smaller quantity; but all plants, when once treated with boron, were kept continuously supplied with it throughout the experiment.

Those which received boric acid from the start soon made more rapid growth than the untreated plants, all flowering well, and the set grown without $\mathrm{H}_{3} \mathrm{BO}_{3}$ for only ten days appeared very similar. However, twenty or thirty days' growth in the absence of boron had a decidedly bad effect. Three of these plants showed the typical 'dying off' of the main shoot, previously described as characteristic of broad beans grown without boron, and the remainder were poor and backward. In one case, 'dying off' occurred a few days after $\mathrm{I}: 2,500,000 \mathrm{H}_{3} \mathrm{BO}_{3}$ had been supplied, which suggested that the physiological condition of the plant, of which this withering was the outward expression, had already set in before treatment. After forty days' growth without boric acid, only three of the ter plants were still healthy, and after fifty days a single plant remained normal in appearance, while all those deprived of boron for sixty days were characteristically withered (Pl. XIII, Fig. 6).

It was noticeable that few plants flowered while still in the normal culture solution, and that though the 'dying off' phenomenon was of general occurrence, the time of its appearance was quite irregular. In two plants, signs of withering set in within twenty-four days, while in others it did not appear until forty-six days' growth. However, in all cases it occurred before the plants were harvested, unless boric acid was supplied in time.

1 The unit was originally $\mathrm{s}$, but owing to the death of numerous seedlings in a spell of hot weather it had to be reduced to 5 . 
The remarkable feature, however, in this experiment, was the recovery of the plant subsequent to the addition of boric acid. In every case (except a few of those deprived of boron for sixty days), though withering had apparently taken a complete hold of the plant, some renewal of growth took place, whether it was merely the production of a few new roots, or the development of a large secondary shoot and an almost entirely new root system (Pl. XIII, Figs. 3 and 4). It would seem, therefore, that boron is able to benefit the plant even at a late stage in its growth, though its effect is certainly less pronounced than when supplied before the injury due to its absence is too far advanced.

(a) General type of recovery subsequent to the addition of boric acid. The individual history of one of the plants showing recovery is interesting and may be taken as typical of the majority of others (Pl. XIII, Fig. 4).

i. The plant was grown in normal solution for twenty days and then placed in a similar solution which contained $\mathrm{I}: 2,500,000 \mathrm{H}_{3} \mathrm{BO}_{3}$.

ii. Four days later, signs of 'dying off' in the shoot were evident. (Possibly the preliminary stages of withering had been overlooked when the plant was transferred, or the disorganization may conceivably have already set in, though not have been visible.)

iii. Fourteen days later the shoot was still very poor, but fresh growth was taking place in the root. The short, thick roots, typical of plants grown in the absence of boron, began to elongate into long, fine ones, and entirely new laterals were also produced. At an early stage in this renewal of growth, the line of demarcation between the old and new portion of the root was clearly defined, and presented a most curious appearance.

iv. Nineteen days later, though the main shoot still remained withered, a healthy secondary shoot was in flower. Besides being considerably larger than the original shoot, this secondary branch was different in appearance from the main axis. The leaves were rather lighter in colour, thin and not leathery in texture, giving the whole shoot an almost succulent appearance. By this time the root system was composed of a dense mass of laterals, though formerly there had been only a few short and thickened roots.

In some cases apparently healthy tillers were produced by plants grown without boron. At first sight, this appeared to be conflicting with the view that it was the presence of boric acid that caused the renewal of growth. However, such tillers never flowered, always remained stunted, and eventually ' died off' in a similar manner to the main axis.

In a few isolated cases, another type of recovery took place. The plant did not show any definite signs of 'dying off' when transferred to the solution containing boric acid, although it had been grown for a very considerable time without boron and was in a poor condition. After thirty days' treatment, a number of fresh green leaves were noticed at the apex of 
the main shoot, though the lower leaves remained yellow and unhealthy. In two of these cases a new supply of flowers was produced at the apex, although the former ones had withered before maturing and had fallen off. It seems probable, therefore, that as these striking recoveries were of such universal occurrence throughout the experiment, the assumption that the addition of boric acid was responsible for the renewed growth was justifiable.

(b) Effect of the concentration of boric acid supplied. On the whole there was but little difference noticed between the plants treated with the

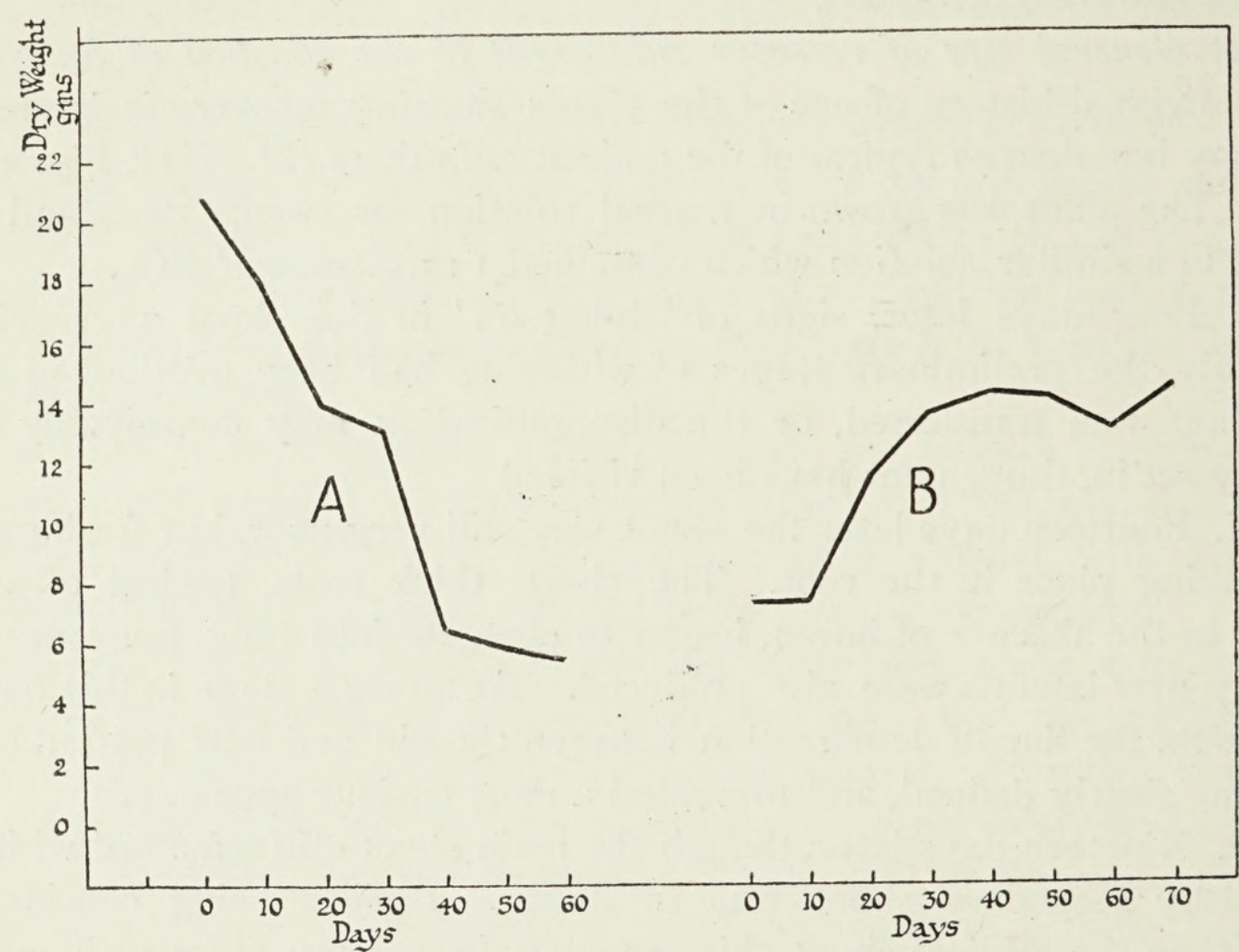

TExT-FIG. 3. Total dry weight of broad beans (average of five plants).

A. Grown without boric acid for different periods; I : 50,000 then added. May 2 IJuly 26 , I922.

B. Grown with boric acid for different periods; 1 :50,000 then removed. Aug. 9Oct. I 8, I 922 .

larger and smaller quantity of $\mathrm{H}_{3} \mathrm{BO}_{3}$ respectively. However, there was one distinct exception, viz. the set of plants grown for thirty days before treatment with boron. In this case those receiving $\mathrm{I}: 2,500,000 \mathrm{H}_{3} \mathrm{BO}_{3}$ were clearly poorer than the corresponding set treated with $\mathrm{I}: 50,000 \mathrm{H}_{3} \mathrm{BO}_{3}$; 'dying off' was also more prevalent among the former. It seems probable that at this time, and under these conditions, a critical stage in the growth of the plants had been reached owing to the deficiency of boron, and that consequently the plants were particularly sensitive to its action. The application of a large quantity would naturally remedy the deficiency more rapidly, and possibly even prevent the appearance of the withering ; a small application, however, such as $I: 2: 500, c 00$, though eventually able to 
bring about recovery, would conceivably be insufficient to check the 'dying off', and the appearance of this phenomenon in several plants can be thus accounted for.

The dry weight values (Table II and Text-fig. 3, A) are in a more or less strict downward sequence from those plants which were continuously supplied with boric acid to those which were treated for a few days only. Allowing for individual variation, the actual concentration of boric acid supplied is seen to have had little effect on the dry weight, except in the case to which attention has already been drawn, and possibly in this case also individual variation may have caused the result to be unduly accentuated.

\section{TABLE II.}

Mean Dry Weight of Broad Beans supplied with Boric Acid at Different Stages of Growth.

May 21-July 26, 1922. Average of 5 plants.

\begin{tabular}{|c|c|c|c|c|c|c|c|c|}
\hline $\begin{array}{l}\text { Days } \\
\text { without }\end{array}$ & $d$ & Days & $1:$ &,$\infty \circ \mathrm{H}_{3}$ & $B O$ & I $: 2$ & ১০,০০০ & $\mathrm{I}_{3} \mathrm{BO}_{3}$. \\
\hline $\mathrm{H}_{3} \mathrm{BO}_{3}$ & $b v$ & $\mathrm{H}_{3} \mathrm{BO}_{3}$. & Root. & & Total. & Root. & Shoot. & Total. \\
\hline 0 & & 66 & 3.94 & $\begin{array}{r}16.83 \\
\end{array}$ & 20.77 & $3 \cdot 32$ & I $4 \cdot \mathrm{I} 6$ & $17 \cdot 4^{8}$ \\
\hline IO & & $5^{6}$ & $3 \cdot 18$ & $\mathrm{I}_{4} \cdot 84$ & 18.02 & 3.22 & I $5 \cdot \mathrm{I} 5$ & 18.37 \\
\hline 20 & & $4^{6}$ & 2.67 & $\mathrm{II} \cdot \mathrm{I} 8$ & 13.85 & $2 \cdot 26$ & $9 \cdot 4^{\mathrm{I}}$ & 11.67, \\
\hline 30 & & $3^{6}$ & 2.60 & 10.40 & I.3.00 1 & $\mathrm{I} \cdot 28$ & 4 . II & $5 \cdot 39^{1}$ \\
\hline 40 & & 26 & $\mathrm{I} \cdot \mathrm{I} 2$ & $5 \cdot 30$ & $6 \cdot 4^{2} 1$ & $\mathrm{I} \cdot \mathrm{I} 5$ & $5 \cdot 4^{2}$ & $6.57^{1}$ \\
\hline 50 & & I6 & I.I 6 & $4 \cdot 65$ & $5 \cdot 8 \mathrm{I}^{1}$ & 1.00 & 5.03 & $6 \cdot 03^{1}$ \\
\hline 60 & & 6 & 0.80 & $4 \cdot 65$ & $5 \cdot 45^{12}$ & $0.5 \mathrm{I}$ & $2 \cdot 4^{2}$ & $2.93^{1,2}$ \\
\hline
\end{tabular}

\section{$\gamma$. The Effect of removing Boric Acid at Different Stages of Growth.}

On transferring a few plants grown for twenty days in a nutrient solution containing $\mathrm{I}: 50,000 \quad \mathrm{H}_{3} \mathrm{BO}_{3}$ to ordinary culture solution, it was evident that a deficiency of boron was felt, as 'dying off' set in after about three weeks. Accordingly, an experiment was set up to see the result of depriving plants of boron after being supplied with $\mathrm{H}_{3} \mathrm{BO}_{3}$ for different periods, since apparently the boron absorbed in twenty days was inadequate for the whole growth period.

Besides the usual nutrient salts, half the plants were treated with $\mathrm{I}: 5^{\circ}, 000$ $\mathrm{H}_{3} \mathrm{BO}_{3}$ and the other half with $\mathrm{I}: 2,500,000 \mathrm{H}_{3} \mathrm{BO}_{3}$. In addition, ten plants received no boric acid at all. All the solutions were renewed every ten days, five plants hitherto treated with one or other of the two strengths of boric acid being placed in ordinary culture solution at each change, and not

1 Average of three plants only, as the remainder were carried on longer for observations on the recovery.

2 These plants may be regarded as controls, as the application of boric acid had no apparent effect during the 6 days. 
again supplied with boric acid throughout the experiment. In order to prevent the transference of small traces of boron after the change, the roots were washed with distilled water, and as long as the size of the plants allowed of it clean bottles were used.

The untreated set soon fell considerably behind all the others; the short, thick type of root previously described for plants grown in the absence of boron was less evident, though the whole root system was poor. Seasonal conditions probably account for this, and the question is more fully discussed farther on.

Another peculiarity of the plants receiving no boron was the outgrowth of numerous secondary branches. None of these tillers flowered, and in all respects they closely resembled the type of growth of the main axis. Brenchley $(11(a))$ has described a similar bushiness of growth in peas supplied with toxic doses of boric acid; but in the case of broad beans it would seem that the absence of an essential element was the factor concerned.

(a) Death subsequent to the removal of boric acid. Each set as it was in turn deprived of boric acid gradually showed the characteristic 'dying off', usually from three to six weeks after the transference into the normal culture solution had been made.

Five weeks from the start of the experiment all the untreated plants, and several of those treated for ten days only, had begun to wither, while those which had been supplied with boric acid for thirty or more days were in flower and still growing rapidly. Although treatment for ten days was hardly beneficial, twenty or thirty days' growth in boric acid caused a marked improvement, and a further superiority was seen in those supplied with $\mathrm{H}_{3} \mathrm{BO}_{3}$ for longer periods.

After seventy days, all the plants which had been treated with I : $50,000 \mathrm{H}_{3} \mathrm{BO}_{3}$ were harvested. At this time, all such plants deprived of boron for forty days or longer were 'dying off', but the remainder, with a single exception, were still healthy whether they had already been transferred to the normal solution or were still supplied with boric acid. The I : 2,500,cco sets, however, were carried on for twenty-six days longer, no further change in their solutions being made, all except five of the plants being already in the ordinary culture solution.

At the end of this period every plant was either severely withered or at least showing signs of dying at the apex of the shoot, except the set of five which were still receiving boric acid; the latter were perfectly healthy and even still flowering (Pl. XIII, Fig. 7).

It is clear, then, that a continual supply of boron enables the broad bean to make normal development, and that a comparatively large quantity given during the first few weeks of growth is less effective than a small amount supplied continuously.

(b) Effect of the concentration of boric acid supplied. For the first week 
or so, little if any difference was evident between the plants treated with the two concentrations of boric acid, viz. I : 50,000 and I : 2,500,000; but a contrast became apparent later, being especially marked in the sets grown for twenty days in the two solutions (Table III). Three weeks after the removal of $\mathrm{H}_{3} \mathrm{BO}_{3}$ all the plants previously treated with the smaller quantity were 'dying off', while those grown in the stronger solution were perfectly healthy and still in flower. In general 'dying off' set in about three to five weeks after the removal of boron where $\mathrm{I}: 2,500,000 \mathrm{H}_{3} \mathrm{BO}_{3}$ had been supplied, while withering was not apparent until four and a half to six weeks after the plants were transferred from a solution containing $\mathrm{I}: 50,000 \mathrm{H}_{3} \mathrm{BO}_{3}$, so that, on the whole, the larger quantity of boron was of more value to the plant than the smaller application, when the treatment lasted for a limited period only.

The upward sequence of the dry weights (Table III and Text-fig. 3, B) as the treatment with boric acid was prolonged corroborates what has already been described. It is evident that but little dry matter is laid down after 'dying off' occurs, for of the plants which were carried on for the additional twenty-six days, only those which did not show signs of withering at the beginning of this period, i.e. those supplied with $\mathrm{H}_{3} \mathrm{BO}_{3}$ for at least forty days, were able to continue growth.

\section{TABLE III.}

Mean Dry Weights of Broad Bean Plants deprived of Boric Acid at Different Stages of Growth.

Average of 5 plants.

\begin{tabular}{|c|c|c|c|c|c|c|c|c|}
\hline \multirow[b]{2}{*}{$\begin{array}{l}\text { Days in } \\
\mathrm{H}_{3} \mathrm{BO}_{3} \text {. }\end{array}$} & \multicolumn{4}{|c|}{$\begin{array}{l}\text { Aug. 9-Oct. I8, I922. } \\
\text { I : } 50,000 \mathrm{H}_{3} \mathrm{BO}_{3} .\end{array}$} & \multicolumn{4}{|c|}{$\begin{array}{l}A u g .9-N o v . \text { I3, I922. } \\
\text { I : } 2,500,000 H_{3} B O_{3} \text {. }\end{array}$} \\
\hline & $\begin{array}{l}\text { Days without } \\
\mathrm{H}_{3} \mathrm{BO}_{3} .\end{array}$ & $\begin{array}{l}\text { Root. } \\
\text { grm. }\end{array}$ & $\begin{array}{l}\text { Shoot. } \\
\text { grm. }\end{array}$ & $\begin{array}{l}\text { Total. } \\
\text { grm. }\end{array}$ & $\begin{array}{l}\text { Days without } \\
\mathrm{H}_{3} \mathrm{BO}_{3} \text {. }\end{array}$ & $\begin{array}{l}\text { Root. } \\
\text { grm. }\end{array}$ & $\begin{array}{l}\text { Shoot. } \\
\text { grm. }\end{array}$ & $\begin{array}{l}\text { Total. } \\
\text { grm. }\end{array}$ \\
\hline$\circ$ & 70 & 0.95 & $6 \cdot 2 \mathrm{I}$ & $7 \cdot 16$ & 96 & $0.8 \mathrm{I}$ & 5.86 & 6.67 \\
\hline IO & 60 & $\mathrm{I} \cdot 26$ & 6.08 & $7 \cdot 34$ & 86 & 1.00 & 6.53 & $7 \cdot 53$ \\
\hline 20 & 50 & I. 88 & $9 \cdot 4^{6}$ & II. 34 & $7^{6}$ & $\mathrm{I} .53$ & $7 \cdot 20$ & 8.73 \\
\hline 30 & 40 & $2 \cdot 26$ & $11 \cdot 22$ & 13.48 & 66 & I. 66 & $9 \cdot 4^{6}$ & $\mathrm{II} \cdot \mathrm{I} 2$ \\
\hline 40 & 30 & 2.53 & II 60 & $14 \cdot 13$ & 56 & 2.55 & 13.89 & I 6.44 \\
\hline $5^{\circ}$ & 20 & $2 \cdot 49$ & II $\cdot 46$ & I 3.95 & $4^{6}$ & 2.90 & 14.70 & 17.60 \\
\hline 60 & IO & $2 \cdot 38$ & $10.7 \mathrm{I}$ & I 3.09 & 36 & $3 \cdot 7 \mathrm{I}$ & 15.74 & $19 \cdot 45$ \\
\hline 70 & 0 & 3.04 & II. 23 & $\mathrm{~J} 4.27$ & 0 & $3 \cdot{ }^{2} 5$ & 16.08 & 19.23 \\
\hline
\end{tabular}

From the foregoing experiments it is clear that a small quantity ${ }^{1}$ of boron supplied some factor essential to the growth of the broad bean plant that was lacking in the usual nutrient solution.

Mazé (23), in a somewhat similar manner, has claimed that among other elements boron is essential to the development of Zea Mays.

1 The total quantity of boric acid supplied varied with the duration of the experiment from $\mathrm{I} \cdot 20$ to $2.64 \mathrm{mg} . \mathrm{H}_{3} \mathrm{BO}_{3}$ where the concentration was $\mathrm{I}: 2,500,000$. On an average each plant would have access to $0.2 \mathrm{mg}$. boric acid per week, but it has not yet been ascertained whether the whole of the quantity is taken up. 
The presence of boron in a large number of plants in nature has been frequently described, and in the present instance it has been detected in garden-grown broad beans, a larger proportion being present in the pods than in the stems or leaves; Cook (16), also, has drawn attention to the occurrence of boron in plants grown as controls to those on boron-treated plots. But in these experiments boron was detected in the dried shoots of broad beans grown entirely in ordinary nutrient solution. The question at once arose as to the origin of the boron in this case, and also as to why such considerable growth was possible before the deficiency made itself evident.

Three possible sources of boron to the plant grown in water culture are :

(I) Atmosphere.

(2) Nutrient solution.

(3) Seed.

(I) The possibility of the plant obtaining boron from the atmosphere may be regarded as quite unlikely.

(2) Qualitative analysis of the nutrient solution showed that it was not responsible for any supply of boron.

(3) The seed, therefore, remained the probable source of the element. Accordingly a large number of broad bean seeds, such as had been used for the water-culture experiments, were ground up into a fine meal and a chemical analysis made, the method used being that described by Bertrand and Thomas (5). The free end of the turmeric paper turned a bright red colour, indicating the presence of boron. The reaction was so definite that in all probability a comparatively large quantity of boron was present; this would explain the great length of time during which healthy growth was maintained by the broad bean before the deficiency became apparent.

ס. The Effect of the Removal of the Cotyledons on Subsequent Growth in Water Culture.

Since boron is apparently of such fundamental importance to the broad bean plant, it seemed probable that removal of the cotyledons, in themselves a source of boron, before growth in water culture, would show up more clearly any difference between plants treated with $\mathrm{H}_{3} \mathrm{BO}_{3}$ or supplied with the usual nutrient salts only.

Many authors, from quite early times, have shown that removal of the cotyledons or endosperm from the embryo resulted in impaired growth and vigour. Both Bonnet (9) and Sachs (32) described this in their work on Phaseolus multiflorus. More recent work on the subject has been done by Andronescu (2) on Zea Mays and Duggar (18) on Canada field peas and field corn.

Difficulty was experienced at first in growing the dissected out plantlets, the method tried at the outset being as follows: the seeds were 
soaked in water overnight, and the plumule and radicle dissected out the next morning and placed on a porous pot standing in nutrient solution. Slight growth was made, but all died after a few days. The use of a nutrient solution with the addition of organic matter such as glucose or mannite gave rather better results, but fungal and bacterial growth made this method unsuitable.

Finally, it was decided to allow germination to start in damp sawdust and not to attempt to grow the young plants until the radicle was about an inch long. At this stage the plumule was in most cases quite yellow, but had sometimes turned green. It was found almost impossible to obtain seedlings uniform in their development, but care was taken to put the strongest of them in the control solution, so that any error thus introduced should be in favour of those deprived of boric acid. Eight of these decotyledoned seedlings were set up in ordinary nutrient solution, four of which received in addition $I: 50,000 \mathrm{H}_{3} \mathrm{BO}_{3}$. As a further contrast a seedling still retaining its cotyledons was set up in each kind of solution.

From the first the seedlings which had been divested of their cotyledons fell very much behind the untreated plants, and they never attained anything approaching normal development. Growth was so slow that even after twenty days in the solution only a few laterals had been developed, and after forty-two days there was but little difference to be seen between those supplied with $\mathrm{H}_{3} \mathrm{BO}_{3}$ and the control plants. However, a week later, when some of the plants were beginning to flower, the controls fell behind, and in some cases signs of 'dying off' were evident. In time, all the plants deprived of boric acid showed this phenomenon, but in no case was there the slightest indication of withering among those supplied with boric acid, either in the untreated or de-cotyledoned plants.

Qualitative analyses of soaked or germinated seeds showed that not only the cotyledons but also the plumule and radicle contained a relatively large proportion of boron. Removal of the cotyledons did not, therefore, completely deprive the plantlets of the element, and this would account for the considerable growth made by the untreated plants. Some food materials also would have been absorbed by the plantlets from the cotyledons during germination, and it is possible that a transference of boron took place at the same time, thus further augmenting the supply. It is also probable that, under these conditions of extremely slow growth, a quantity of boron which under ordinary circumstances would have been entirely inadequate for so long a period, was sufficient to meet the demands of the plant.

\section{B. Barley.}

In I9I 4 Brenchley (I I $(a)$ ) described a series of water-culture experiments on the action of boric acid on barley. The present investigation was carried out on somewhat similar lines to obtain a comparison both with the 
earlier work and also with the experiments on the broad bean here described. In general, the results are in close agreement with those of Brenchley, in spite of the fact that in the IgI 4 work the nutrient solutions were never renewed and the plants were harvested at a comparatively early stage, so that the action of boron is apparently similar whether in the presence of a plentiful or restricted food supply. The barley seed used in $192 \mathrm{I}$ was an unnamed pure strain from Professor Biffin, but in the following season the variety was pure line Goldthorpe from Leamington. In each case the seed was graded by weight to within $0.01 \mathrm{grm}$.

\section{a. The Effect of Different Concentrations of Boric Acid in the Nutrient} Solution.

In the preliminary experiment the effect of a wide range of concentrations was tried, viz. from $\mathrm{I}: 5,000$ to $\mathrm{I}: 100,000,000$. Five plants were taken as the unit in this case.

(a) Development of the root. The plants treated with $\mathrm{I}: 5,000 \mathrm{H}_{3} \mathrm{BO}_{3}$ showed the injurious effect of boron after as little as three days' growth in the solution. The roots were thick and short, and curled root-tips were noticed in several cases. Later a number of long, fine laterals were produced, resulting in a bushy appearance. A gradual improvement in the root development was evident as the concentration of boric acid was reduced, no bushiness being noticeable when less than $\mathrm{I}: 50,000 \mathrm{H}_{3} \mathrm{BO}_{3}$ was given, while the $1: 2,500,000$ and weaker sets closely resembled the untreated plants.

(b) Development of the shoot. The I : 5,000 set soon showed the toxic effect of boron. The leaves turned yellow at the tip, and later brown spots appeared, beginning at the apex and margins and gradually covering the entire leaf-blade. As fresh growth was produced it was rapidly affected in the same way, the injury always appearing first in the lower leaves. The nature and mode of progression of the poisoning action were exactly similar to that previously described by Brenchley $(11(a))$. The leaves were small and narrow, and in every case the plants were poor and scarcely tillered and never came into ear. The flecking of the leaves gradually disappeared as the quantity of boric acid supplied was decreased, and in the plants grown with I : 500,000 and I: 2,500,000 the discoloration was very slight; both these sets also came into ear. The plants grown in I : 2,500,000 and I : I 2,500,000 $\mathrm{H}_{3} \mathrm{BO}_{3}$ were the best in this series. They were taller and a darker colour than the controls and appeared particularly healthy. This dark-green coloration is apparently typical of plants treated with non-toxic doses of boric acid, and has also been previously noticed.

No stimulating effect, however, was apparent in the plants grown with I : $100,000,000 \mathrm{H}_{3} \mathrm{BO}_{3}$; they in all ways closely resembled the controls, the latter being healthy and well grown. 
3. Comparison between the Effect of Boric Acid and Borax in the Nutrient Solution.

Borax and boric acid were used in such quantities that an equivalent amount of boron was supplied in each case ; i. e. I grm. $\mathrm{H}_{3} \mathrm{BO}_{3}=\mathrm{I} \cdot 54 \mathrm{grm}$. $\mathrm{Na}_{2} \mathrm{~B}_{4} \mathrm{O}_{7}$. Io $\mathrm{H}_{2} \mathrm{O}$. It was uncertain whether boron in the form of the salt would prove more or less toxic than when presented as the acid.

The range of concentrations in this case was from $1: 50,000$ to I : I00,000,000 $\mathrm{H}_{3} \mathrm{BO}_{3}$, since any heavier dose was obviously toxic. Ten plants were taken as the unit.

As might be expected from the results of the previous experiments, no very toxic action was noticeable with any of the concentrations of boric acid used, except in the $I: 50,000$ set. In this case, however, a distinct bushiness of the root resulting from an outgrowth of fine laterals from short and thickened roots was shown, and the leaves also were badly spotted. However, in the plants receiving an equivalent amount of boron in the form of borax no bushiness of the root was apparent, though the development was poor. This was the only definite indication that the action of borax was less toxic than that of boric acid, for in other respects the plants appeared similar, e.g. the leaves were affected in much the same degree, and even the dry weights of the roots were of the same order. All the remaining sets showed a gradual improvement corresponding to the reduction in the concentration of boric acid or borax. As in the previous experiment, the discoloration of the leaf was practically negligible at a concentration of $\mathrm{I}: 2,500,000 \mathrm{H}_{3} \mathrm{BO}_{3}$. The $\mathrm{I}: \mathrm{I} 2,500,000 \mathrm{H}_{3} \mathrm{BO}_{3}$ and the corresponding borax set were decidedly the best of the whole series; the controls, though perfectly normal and healthy, lacked the luxuriant growth and the dark colour of these plants (P1. XIII, Fig. 8). On the whole, the borax-treated plants seemed slightly superior to the corresponding sets supplied with boric acid, and, though no actual measurements were made, the transpiration rate was apparently greater in the former, which would support this view; however, a comparison of typical individuals showed that there was no appreciable difference (Pl. XIII, Fig. 9).

Discussion of dry weights. From a comparison of the dry weight figures (Tables IV and V and Text-fig. 4) it is evident that concentrations as low as $\mathrm{I}: 2,5 \mathrm{co}, 000 \mathrm{H}_{3} \mathrm{BO}_{3}$ exerted a definitely toxic effect, which was more accentuated as the quantity of boric acid increased. Below $1: 2,500,000$, however, no injurious action was apparent, and in one experiment there was some slight indication of stimulation in the dry weight, but this may possibly be rather attributed to individual variation.

The absence of any increase over that of the controls in the dry weights of plants supplied with $\mathrm{I}: \mathrm{I} 2,500,000 \mathrm{H}_{3} \mathrm{BO}_{3}$ was however unexpected, since to the eye the untreated plants were distinctly the smaller. In all probability these larger plants contained a higher percentage of water and 
an increase in the green weight might have been realized. (The fresh weight of plants in water culture is difficult to determine with any accuracy, owing to the wet condition of the roots.) These plants also seemed to be less mature than the controls, the boron possibly exerting some retarding effect. Consequently, if the plants had been harvested at a later stage, some increase in the dry weight might reasonably have been expected to be shown. Should this suggestion be justifiable, the slight indication of stimulation which was obtained in the preliminary experiment, where the plants were

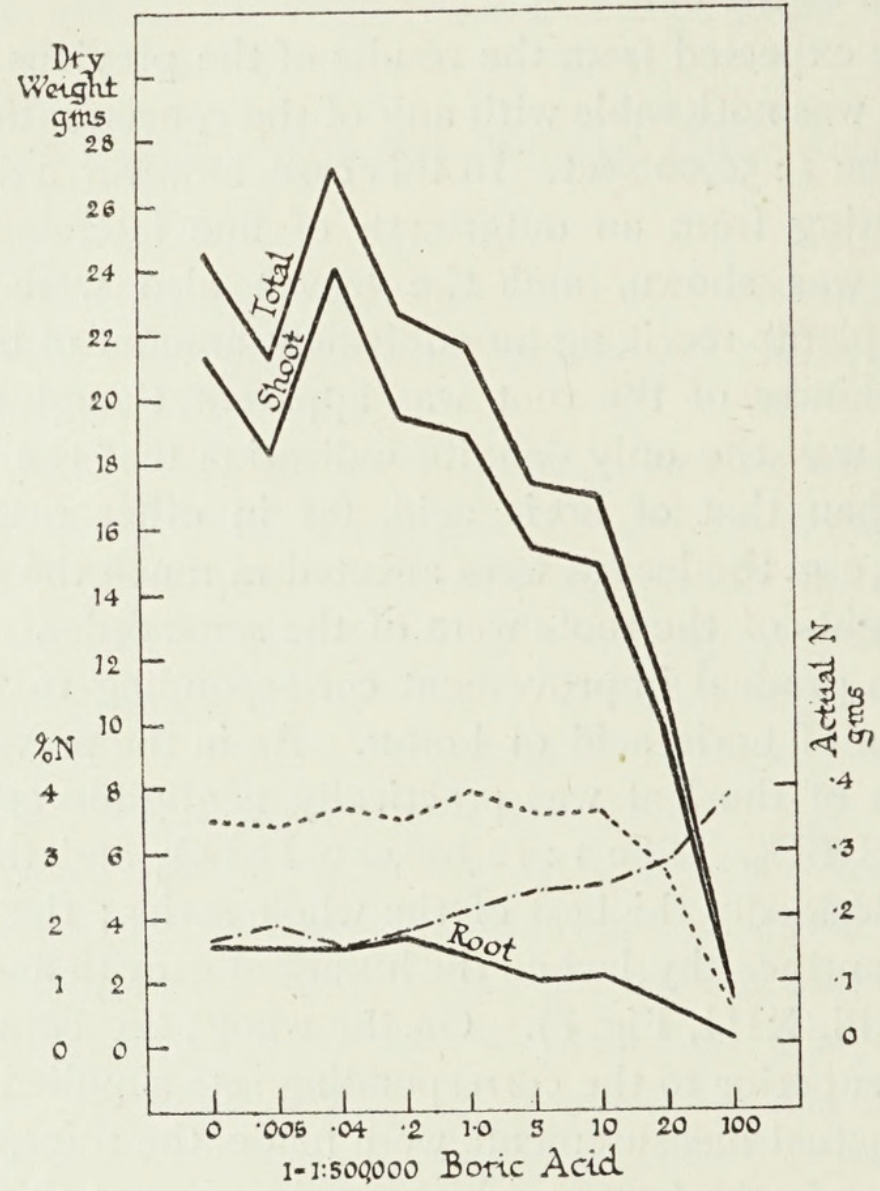

TEXT-FIG. 4. Barley grown in water-culture solution containing different quantities of boric acid. Feb. 2I-May 24, I $9^{2}$ I (average of five plants): — Dry Weight; - - - - - per cent. Nitrogen; -...- Actual N.

not harvested until in ear, may possibly be of real import. However, the evidence is too incomplete for any definite conclusions to be drawn. The difference between plants treated with equivalent amounts of boric acid and borax is not significant, but on the whole the borax-treated plants gave a slightly higher dry weight figure than the corresponding sets treated with boric acid.

No definite relationship was shown between the $\frac{\text { shoot }}{\text { root }}$ ratios of the variously treated barley plants, as was noticed in the case of the broad bean. It would seem, therefore, that in the case of barley the root and shoot are affected more or less equally by the boron compound. 
TABLE IV.

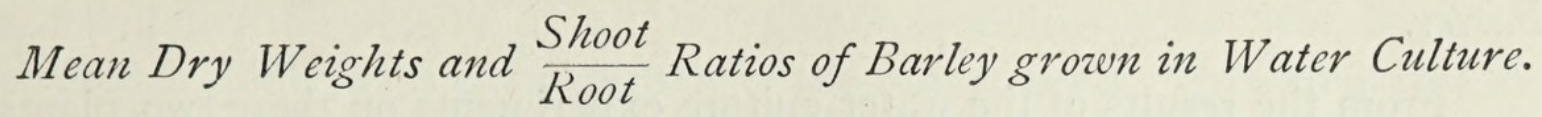
(Average of $3^{-5}$ plants. ${ }^{1}$ )

Feb. 2 1-May 24, I92I.

\begin{tabular}{|c|c|c|c|c|}
\hline $\begin{array}{c}\text { Concentration } \\
\text { of } \mathrm{H}_{3} \mathrm{BO}_{3} \text {. }\end{array}$ & Root. & Shoot. & Total. & $\frac{\text { Shoot }}{\text { Root }}$ \\
\hline Control & $\begin{array}{l}\text { grm. } \\
3 \cdot 12\end{array}$ & $\begin{array}{l}\text { grm. } \\
2 \mathrm{I} \cdot 33\end{array}$ & $\begin{array}{c}\text { grm. } \\
24.45 \pm 0.17\end{array}$ & $6 \cdot 8_{4}$ \\
\hline I : $100,000,000$ & $2 \cdot 9 I$ & $18 \cdot 3^{I}$ & $2 I \cdot 22 \pm 1 \cdot 3^{2}$ & $6 \cdot 29$ \\
\hline I : I 2, 500,000 & $2 \cdot 99$ & $24^{\circ} 00$ & $26.99 \pm 0.15$ & $8 \cdot 03$ \\
\hline I : $2,500,000$ & $3 \cdot 19$ & $19 \cdot 43$ & $22 \cdot 62 \pm 0.7 \mathrm{I}$ & $6 \cdot$ I I \\
\hline I : 500,000 & $2 \cdot 70$ & 18.85 & $2 \mathrm{I} \cdot 55 \pm 0 \cdot 5 \mathrm{I}$ & $6 \cdot 9^{8}$ \\
\hline I : 100,000 & $I \cdot 94$ & I $5 \cdot 44$ & $17 \cdot 38 \pm 0.96$ & $7 \cdot 96$ \\
\hline I : 50,000 & $2 \cdot 14$ & $\mathrm{I} 4 \cdot 82$ & $16.96 \pm 0.23$ & $6 \cdot 93$ \\
\hline I $: 25,000$ & $I \cdot 22$ & $9 \cdot 72$ & $10.94 \pm 1 \cdot 47$ & $7 \cdot 97$ \\
\hline I $: 5,000$ & $0 \cdot 15$ & $\mathrm{I} \cdot 4^{2}$ & $\mathrm{I} \cdot 57 \pm 0 . \mathrm{I} 7$ & $9 \cdot 4^{6}$ \\
\hline
\end{tabular}

\section{TABLE V.}

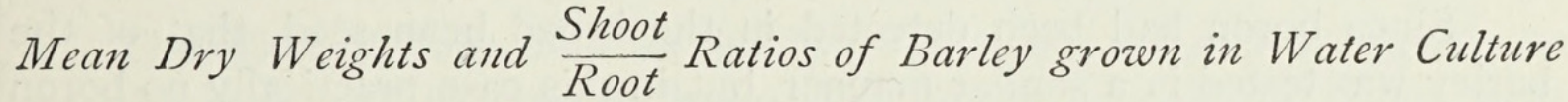
with Boric Acid or Borax containing equivalent quantity of Boron. (Concentrations given as $\mathrm{H}_{3} \mathrm{BO}_{3}$.)

March I-May II, 1922 (average of 5 plants).

Plants in the centre of the Greenhouse. ${ }^{2}$

\begin{tabular}{|c|c|c|c|c|c|c|c|c|}
\hline \multirow{2}{*}{$\begin{array}{l}\text { Concentration } \\
\text { of } \mathrm{H}_{3} \mathrm{BO}_{3} \text {. }\end{array}$} & \multicolumn{3}{|c|}{ Boric Acid. } & \multirow{2}{*}{$\frac{\text { Shoot }}{\text { Root }}$. } & \multirow{3}{*}{$\begin{array}{l}\text { R'oot. } \\
\text { grm. }\end{array}$} & \multicolumn{2}{|c|}{ Borax. } & \multirow{2}{*}{$\frac{\text { Shoot }}{\text { Root }}$} \\
\hline & & Shoot. & Total. & & & & & \\
\hline & $\begin{array}{l}\text { grm. } \\
\mathrm{I} \cdot 53\end{array}$ & $\begin{array}{l}\text { grm. } \\
9^{\circ} 37\end{array}$ & $\begin{array}{l}\text { grm. } \\
\text { I0.90 }\end{array}$ & $6 \cdot I$ & & $\begin{array}{l}\text { grm. } \\
9 \cdot 37\end{array}$ & $\begin{array}{l}\text { grm. } \\
\text { I0.90 }\end{array}$ & $6 \cdot I$ \\
\hline I : $100,000,000$ & $I \cdot 60$ & $8 \cdot 9^{2}$ & $10.5^{2}$ & $5 \cdot 6$ & $I \cdot 76$ & $9 \cdot 74$ & $11 \cdot 50$ & 5.5 \\
\hline I : I 2,500,000 & $I \cdot 6 I$ & $9 \cdot 08$ & $10 \cdot 69$ & $5^{\cdot} \cdot 6$ & $I \cdot 64$ & $9 \cdot 47$ & $I I \cdot I I$ & $5 \cdot 8$ \\
\hline I : $2,500,000$ & $\mathrm{I} \cdot 44$ & $7 \cdot 30$ & $8 \cdot 74$ & $5 \cdot I$ & $1 \cdot 73$ & $8 \cdot 55$ & 10.28 & $4 \cdot 9$ \\
\hline I $: 500,000$ & $1 \cdot 68$ & $7 \cdot 73$ & $9 \cdot 4 \mathrm{I}$ & $4^{\circ} 6$ & 1.55 & $8 \cdot 16$ & $9 \cdot 7 \mathrm{I}$ & $5 \cdot 3$ \\
\hline I : 100,000 & $I \cdot 40$ & 6.88 & $8 \cdot 28$ & $4^{\circ} 9$ & $\mathrm{I} \cdot 3 \mathrm{I}$ & $7 \cdot 47$ & $8 \cdot 78$ & $5 \cdot 7$ \\
\hline I : 50,000 & 0.99 & $5 \cdot 85$ & $6 \cdot 84$ & $5 \cdot 9$ & 0.80 & $5 \cdot 19$ & $5 \cdot 99$ & 6.5 \\
\hline
\end{tabular}

Plants at the side of the Greenhouse.

(Average of 5 plants.)

\begin{tabular}{|c|c|c|c|c|c|c|c|c|}
\hline Concentration & & 50 & Acid. & & & & & \\
\hline of $\mathrm{H}_{3} \mathrm{BO}_{3}$. & Root. & & & Koot & & & Total. & Root \\
\hline Control & $\begin{array}{l}\text { grm. } \\
\text { I. } 90\end{array}$ & $\begin{array}{l}\mathrm{grm} . \\
9 \cdot 78\end{array}$ & $\begin{array}{l}\text { grm. } \\
\text { I I } \cdot 70\end{array}$ & & $\begin{array}{l}\text { grm. } \\
\text { I.90 }\end{array}$ & $\begin{array}{l}\text { grm. } \\
9 \cdot 78\end{array}$ & $\begin{array}{l}\text { grm. } \\
\text { I I · } 70\end{array}$ & \\
\hline I : $100,000,000$ & $1 \cdot 75$ & 8.62 & $10 \cdot 37$ & $4 \cdot 9$ & 2.06 & $9 \cdot 35$ & II. 40 & 4.5 \\
\hline I : I 2,500,000 & 1.62 & 8.27 & $9 \cdot 89$ & $5 \cdot \mathrm{I}$ & $I \cdot 5^{8}$ & $7 \cdot 33$ & $8.9 \mathrm{I}$ & 4.6 \\
\hline I $: 2,500,000$ & $1 \cdot 33$ & $5 \cdot 92$ & $7 \cdot 25$ & $4 \cdot 5$ & $\mathrm{I} \cdot 54$ & 8.02 & $9 \cdot 5^{6}$ & $5 \cdot 2$ \\
\hline I : 500,000 & $\mathrm{I} \cdot 35$ & $5 \cdot 98$ & $7 \cdot 33$ & $4 \cdot 4$ & $\mathrm{I} \cdot 75$ & $7 \cdot 70$ & $9 \cdot 45$ & $4 \cdot 4$ \\
\hline I : I 100,000 & $I \cdot I 6$ & $5 \cdot 87$ & $7 \cdot 03$ & $5 \cdot I$ & I.I 8 & $6 \cdot 10$ & $7 \cdot 28$ & 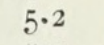 \\
\hline I : 50,000 & 0.83 & $4 \cdot 7^{2}$ & $5 \cdot 55$ & $5 \cdot 7$ & 0.88 & 4.57 & $5 \cdot 45$ & $5 \cdot 2$ \\
\hline
\end{tabular}

1 Reduction in the average number was unavoidably due to death or abnormally poor development of plants.

${ }^{2}$ Owing to lack of space in the greenhonse with similar conditions of illumination, the experiment was divided into two equal parts and the dry weights considered separately. 


\section{$\gamma$. Comparison between the Effect of Boric Acid on Broad Beans and} Barley.

From the results of the water-culture experiments on these two plants, it is evident that barley is less able to stand high concentrations of $\mathrm{H}_{3} \mathrm{BO}_{3}$ than the broad bean, for the latter made excellent growth in a solution which was highly poisonous to barley, viz. I : 50,000 $\mathrm{H}_{3} \mathrm{BO}_{3}$, and further I : I 2,500,000 $\mathrm{H}_{3} \mathrm{BO}_{3}$, which was just below the toxic limit for barley, was barely enough to ensure healthy growth of the broad bean.

Barley, on the one hand, can apparently make approximately optimum growth in the absence of any boron compound, and would therefore seem more or less indifferent to its presence, provided that the quantity is not sufficient to be toxic; on the other hand, the ordinary nutrient solution has been shown to be inadequate for even normal development of the broad bean, but the addition of a small amount of boron is able to supply some factor which is lacking.

Since boron had been detected in the broad bean seed, that of the barley was tested in a similar manner, but in this case practically no boron was found. Some explanation is therefore afforded for the different reaction of the two plants towards the presence of boric acid in the nutrient solution, for the occurrence of an element in the reserve food of the seed might possibly indicate the importance of that element to the plant in question.

\section{Miscellaneous Plants.}

Since the addition of small quantities of boric acid to the nutrient solution caused such striking results in the growth of the broad bean plant, a number of other plants were tested in a similar manner. Although Agulhon $(1(a))$, in particular, has shown that the importance of boron is by no means confined to the Leguminosae, it is evident from several workers, Cook (16) and Morse (26) for example, that certain members of this Natural Order readily respond to its influence. Accordingly the majority of the plants chosen were of this group.

In each case fifteen plants were set up in ordinary culture solution at the beginning of August I922; five receiving in addition I: 2.500,000 $\mathrm{H}_{3} \mathrm{BO}_{3}$ and five $\mathrm{I}: 100,000 \mathrm{H}_{3} \mathrm{BO}_{3}$. All the seeds were graded, with the exception of the clovers.

(a) Phaseolus mulifflorus (Runner Bean-Sutton's Prizewinner).

From the start the plants supplied with boric acid made better growth than the controls, the difference being first noticeable in the better development of lateral roots. Later a distinct difference in the type of root was evident, those in the control solution being short and thick, while the borontreated plants had long fine roots. 
After the plants had been set up in their respective solutions for about a fortnight, the shoots of all the plants receiving boric acid began to elongate rapidly, as is characteristic of the runner bean. No sign of this was seen in any of the five controls. Eventually the boron-treated plants attained a height of several feet and flowered profusely, but the controls remained stunted until the close of the experiment and never even formed flower buds (Pl. XIII, Fig. IO).

Some indication of a toxic influence was evident in the plants grown with I : $100,000 \mathrm{H}_{3} \mathrm{BO}_{3}$ in spite of the marked beneficial effect, for the lower leaves were inclined to turn yellow and some brown patches were seen. Apart from this slightly unfavourable appearance of the plants treated with the larger quantity of $\mathrm{H}_{3} \mathrm{BO}_{3}$, there was little if any difference shown between the plants grown in the two concentrations of boric acid respectively.

\section{(b) Phaseolus vulgaris (Dwarf Bean-Sutton's Canadian Wonder).}

The effect of boric acid on the dwarf bean was not seen so quickly as was the case with the runner bean. For some time all the plants were rather poor, probably owing to seasonal conditions, and it was impossible to note any appreciable difference between the sets, owing to the great lack of uniformity. However, after about three weeks' growth, the boron-treated plants ran ahead of the controls, both shoot and root being better developed, though no striking contrast between the type of root was apparent.

The control plants made very little growth indeed, and eventually all died, yet at first they were even a better green colour than the treated plants; the latter were decidedly yellowish, but grew to fair-sized plants, flowered, and in some cases fruited.

(c) Trifolium incarnatum (Crimson Clover).

This plant gave particularly striking results which were confirmed by further experiments. Even after two days' growth in their respective solutions a difference was noticeable in the root development, those without boric acid showing a curious bending at the tip with a tendency to a constriction behind the bend, while the treated plants did not show this, or at most in a very small degree. Later the lateral roots were distinctly better developed in both sets of plants grown with boric acid than in the controls. Ten days from the start of the experiment the untreated plants had developed a short and stunted root system, while those supplied with boric acid had long, fine roots, the difference becoming more accentuated as growth went on. The time when this abnormal type of root became apparent was evidently dependent upon seasonal conditions, for in the case of some Trifolium incarnatum plants, set up in ordinary nutrient solution in September, the roots for a considerable time closely resembled those which 
were grown with boric acid; after several weeks, however, a contrast was clearly marked, the stunted appearance being quite distinct. In all probability, since growth was so slow at this time of the year, a comparatively long interval was necessary before the deficiency of boron became apparent.

Differences between the shoots of the treated and the control plants were not noticed until after eight weeks' growth even in the case of plants set up in August; but at this time the plants without boron were decidedly the smaller, and the leaves showed a tendency to turn reddish in colour. By December 6 two of these plants were dead and the remainder very poor, no signs of flowering being shown even by the end of February.

The plants supplied with boron, however, grew luxuriantly, those receiving the smaller quantity being of a particularly healthy green colour ; in other respects there was apparently but little difference between the effect of the two concentrations of $\mathrm{H}_{3} \mathrm{BO}_{3}$, and by the middle of February both these sets showed signs of flowering.

A similar series of plants was set up, also in August, but in this case the solutions were not renewed. The results were in close agreement with the former series, but there was no flowering and the untreated plants succumbed rather more quickly.

\section{(d) Trifolium repens (Wild White Clover):}

Very much less difference was seen between the controls and the boricacid-treated plants than was the case with the crimson clover.

The controls were certainly inferior, both in the root and shoot, though the development in each case was perfectly normal. The plants grown with the larger quantity of boric acid were inclined to be yellowish, though those receiving the smaller dose were a good colour and, as regards both the shoot and root development, quite the best of the series.

(e) Pisum sativum (Peas).

(I) Harbinger. For some time no obvious difference was seen between the three sets, but later it was clear that the root system was poorer in the untreated plants; the shoots also were inferior, no flowering occurring in even a single case. On the other hand, the plants supplied with boric acid both flowered and fruited. This lack of flowering may have been due to seasonal conditions, as usually this pea flowers freely in ordinary water culture.

(2) Pioneer. This variety of pea was evidently more susceptible to the influence of boron than the Harbinger, for the contrast between the controls and the plants treated with $\mathrm{H}_{3} \mathrm{BO}_{3}$ was much more marked. In this case also the controls failed to flower, although the treated plants both flowered and fruited. The two concentrations of boric acid had apparently much the same effect. 


\section{(f) Winter Vetch. (g) Rye.}

Hardly any difference was noticeable in either of these plants between those treated with boric acid and the controls. In the case of rye, growth was apparently satisfactory in all the sets, though no ears were formedprobably on account of the unfavourable season of the year. The vetch 'did not flower either.

Although these last few tests have only been carried out on quite a small scale, it seems probable that boron is able to supply some need in the case of several other plants besides the broad bean. Phaseolus multiflorus and Trifolium incarnatum in particular appear to derive especial benefit from treatment with a small quantity of boric acid.

In the earlier work on boron Brenchley $(11(a))$ has stated that lupins were particularly difficult to grow in water culture, since they tended to drop their leaves for no apparent reason. This is somewhat suggestive of the leaf-fall noticed in broad beans deprived of boric acid, and it is possible that lupins may be another instance of a plant benefiting from a continual supply of a minute quantity of boron.

It is hoped to repeat these experiments at the first opportunity, with the addition of several other plants, including yellow and white lupins, in order to investigate the matter more completely.

\section{Pot Cultures.}

Experiments were carried out with both broad beans and barley. Tall, narrow, glazed pots containing $22 \frac{1}{2} \mathrm{lb}$. of soil were used in every case. Owing to the heavy nature of the Rothamsted soil, which renders it difficult to handle in pot-culture work, Io per cent. sand was added, this mixture being found quite satisfactory.

All the pots received a basal dressing of $5 \mathrm{grm}$. superphosphate, I grm. potassium sulphate, and $\mathbf{I} \cdot \mathbf{O}-\mathbf{I} \cdot 5 \mathrm{grm}$. sodium nitrate, whether or not they were further treated with boron compounds.

Five or six pots were taken as the unit.

\section{A. Broad Beans.}

Sutton's Prolific Longpod was used in every case and graded for each experiment, two plants being grown per pot.

a. The Effect of adding Various Quantities of Boric Acid to the Soil.

The effect of a wide range of concentrations of $\mathrm{H}_{3} \mathrm{BO}_{3}$ was tried in the two preliminary experiments; in the first case it was mixed throughout the whole depth of the pot, but in subsequent series it was applied as a top- 


\section{Warington.-The Effect of Boric Acid and Borax on}

dressing, ${ }^{1}$ since this mode of application more closely resembled field methods.

(a) Boric acid mixed throughout the soil $\left(22 \frac{1}{2} \mathrm{lb}\right.$.). 4 grm. of $\mathrm{H}_{3} \mathrm{BO}_{3}$ were strongly toxic; besides being so injurious to the plant, a grey deposit wa's noticed on the surface of the soil, giving it a most unhealthy appearance. This was thought to be due to a surface concentration of a boron compound, since it gave a very strong boron reaction on testing with the turmeric method.

Germination was severely retarded in these pots and the plumules on emerging were frequently yellow, this chlorotic condition remaining for a considerable time in some cases. The retarding influence of boron compounds on the germination of seeds was noticed by Heckle (21) as early as 1875 . Since that date, similar results with a large variety of plants have been obtained by a number of workers on the subject, including Archangeli (3), Morel (25), Agulhon (1 (a)), Voelcker (36), Sherwin (34), Blair and Brown (7), and Neller and Morse (2i).

As growth went on, the plants became light green, but the leaves turned brown along their margins in a manner similar to that described in the water-culture experiments. Spotting of the leaves, as was seen in barley, never occurred. The injury was at first apparent in the lower leaves, but nearly all of them showed it later. Growth was very slow, but eventually several of the plants flowered.

$2 \mathrm{grm} . \mathrm{H}_{3} \mathrm{BO}_{3}$ per pot were decidedly less toxic than $4 \mathrm{grm}$. (Table VI), germination being less retarded and the plants flowering better; however, the leaves were inclined to be yellowish and showed signs of quite severe poisoning; where only $\mathrm{I}$ grm. $\mathrm{H}_{3} \mathrm{BO}_{3}$ was applied, toxic effects were rare, brown leaf-margins being seen in isolated cases only, and the green and dry weights being only slightly depressed (Table VI). Plants receiving lower dressings were quite similar in colour and general appearance to the controls, though some superiority in height was evident where 0.5 or $0.1 \mathrm{grm}$. had been applied. This apparent stimulation was also noticeable in the green weight, an increase of 14.4 per cent. being obtained with the larger quantity; the rise in dry weight, however, was practically negligible (Table VI and Textfig. 5). Neller and Morse (27) have noticed a similar indication of stimulation to the eye in the case of Phaseolus in pot culture, but here also no increase in the dry weight was realized, even the beneficial appearance having disappeared at the close of the experiment.

The untreated plants were in every way perfectly normal: the phenomenon of 'dying off', of universal occurrence in broad bean plants grown in water culture without boron, did not occur in a single instance; in fact the pot-culture control plants closely resembled the sets in water culture which were supplied with low concentrations of boric acid.

\footnotetext{
1 The $\mathrm{H}_{3} \mathrm{BO}_{3}$ was sprinkled evenly over the surface of the soil and the pots watered.
} 
Since small quantities of boron compounds are common constituents of the soil, and traces have been detected in the soils used in this pot-culture work, it is probable that the plant is able to absorb sufficient of the element from the untreated soil to make normal development: if this were not so, it would be difficult to account for the success with which broad beans are usually cultivated in garden soil, though it is still an open question whether growth might not be improved on occasions by the addition of further small quantities of boron compounds.

(b) Boric acid applied as a topdressing. Applied as a top-dressing, boric acid was more toxic than when the same quantity was mixed throughout the soil, and this is borne out by the green and dry weight figures (Table VI). The application was made twenty-four days after sowing. All the plants died when treated with 4 grm. or 2 grm. $\mathrm{H}_{3} \mathrm{BO}_{3}$ per pot, and even I grm. proved very injurious, only a few plants surviving for a short time.

The exceptional drought conditions of $192 \mathrm{I}$, in spite of regular watering of the pots, may have caused this result to be unduly accentuated, but it is to be expected that the boric acid would have a more marked effect on the plant when concentrated in the upper soil layers where the young roots were developing. 0.5 grm. $\mathrm{H}_{3} \mathrm{BO}_{3}$ per

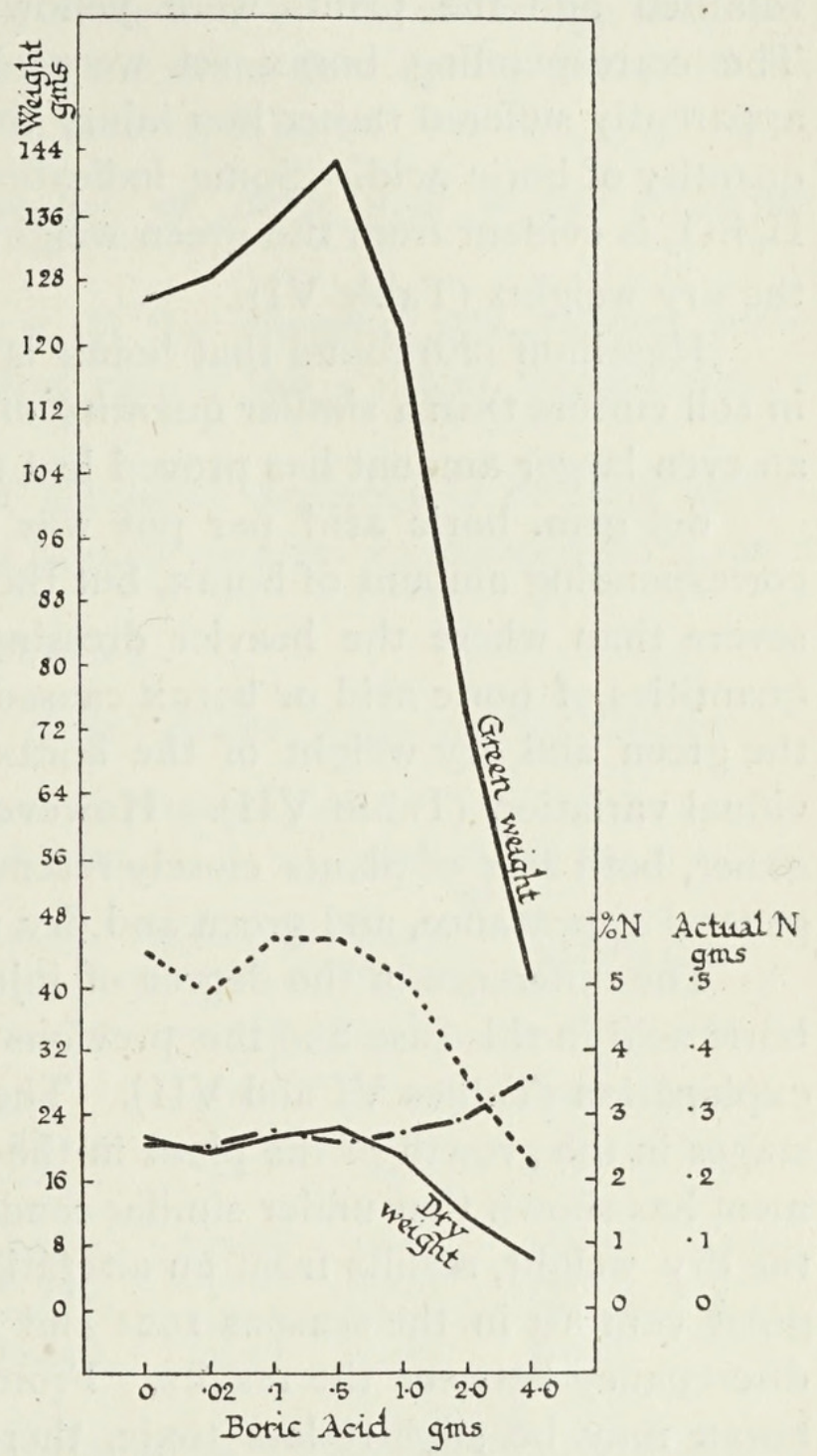

Text-FIg. 5. Broad beans grown in pot culture with various quantities of boric acid mixed throughout the soil. Mar. 4-May 3I, I92 I (average of five pots): - Weight ; - - - - - per cent. Nitrogen ; .... Actual N.

pot was also decidedly injurious, the plants showing the typical leaf poisoning; but $0.1 \mathrm{grm}$. or $0.02 \mathrm{grm}$. caused no toxic effect, the plants in the former set being even slightly taller than the controls, while in both cases a small increase over the untreated plants was obtained in the green and dry weights (Table VI).

\section{Comparison between the Effect of Boric Acid and Borax in the Soil.}

In this series $\mathrm{Na}_{2} \mathrm{~B}_{4} \mathrm{O}_{7}+0 \cdot 10 \mathrm{H}_{2} \mathrm{O}$ was tested simultaneously with 
boric acid, equivalent amounts of boron being supplied in each case $(\mathrm{I} \cdot \mathrm{O}$

boric acid $=1.54$ borax). The top-dressings were applied at the time of sowing.

$1 \mathrm{grm} . \mathrm{H}_{3} \mathrm{BO}_{3}$ was the heaviest dressing given in this experiment, as any larger quantity was strongly toxic. Germination was decidedly retarded and the plants were yellowish green with brown-edged leaves. The corresponding borax set were also very poor plants, though they apparently suffered rather less injury than those treated with the equivalent quantity of boric acid. Some indication of the more poisonous nature of $\mathrm{H}_{3} \mathrm{BO}_{3}$ is evident from the green weight value, but no contrast is shown in the dry weights (Table VI).

Haselhoff (20) found that borax is less injurious to Phaseolus vulgaris in soil culture than a similar quantity of boric acid, but in the present case an even larger amount has proved less toxic.

$0.5 \mathrm{grm}$. boric acid per pot was again slightly more toxic than the corresponding amount of borax, but the injury in both cases was much less severe than where the heavier dressings had been supplied. Still lower quantities of boric acid or borax caused no toxic effect at all, the drop in the green and dry weight of the borax set being most likely due to individual variation (Table VII). However, no beneficial effect was apparent either, both sets of plants closely resembling the controls in colour, height, general appearance, and green and dry weight.

The difference in the degree of injury caused by a dressing of I grm. boric acid in this case and the previous experiment seems to require some explanation (Tables VI and VII). The boric acid was applied at different stages in the growth of the plant in the two cases, but a subsequent experiment has shown that under similar conditions no great difference, at least in the dry weight, results from "an alteration in the time of application. The great contrast in the seasons I 92 I and 1922 more probably accounts for the discrepancy between the results. From this it seems probable that, though borax may be slightly less toxic, there is little if any real differerence between the action of borax and boric acid; which points to the fact that the element boron is the important factor in both cases, as Peligot (28) showed in 1876 .

In order to determine whether these dressings had any marked effect on the root system as well as on the shoot, several roots were washed out from the soil, typical plants being chosen. It was found that in the case of plants treated with either I grm. of $\mathrm{H}_{3} \mathrm{BO}_{3}$ or the corresponding quantity of borax, the roots were long and not at all plentiful, being especially scarce in the surface layers, but tubercle formation was apparently normal. On the other hand, plants receiving a small dose of $\mathrm{H}_{3} \mathrm{BO}_{3}$, e. g. O.I grm., had a large root system similar to the untreated plants. A striking contrast between the root growth of the control plants and that of the heavily 
treated sets was seen, for in the former case only were the roots well developed near the surface, though as regards total length the two cases were very similar. This is quite in accordance with what might be expected, for the roots in the heavily treated pots would natually make most growth in the less toxic region, i. e. other than the surface soil which had received the dressing. A similar result has been described by Breckenridge (10), but as he applied the borax below the seed, the roots developed mainly at the surface, which was in this case the less toxic soil layer.

$\gamma$. Comparison between the Application of Boric Acid at two Different Stages of Growth.

In the preliminary experiment $a(b)$ the dressing was applied some time after sowing, but in the succeeding case $\beta$ the soil was treated before germination had taken place.

Since the time of application of manurial dressings is of such importance in agricultural practice, a series of pots were set up to ascertain if there

TABLE VI.

Mean Green and Dry Weights of Broad Beans grown in Pot Culture.

$$
\begin{aligned}
& \text { Average of } 5 \text { or } 6 \text { pots. } 2 \text { plants per pot. }{ }^{1} \\
& \begin{array}{ccc}
\text { Mar. 4-May 31, April I5-June 29, } \\
\text { I921. }
\end{array} \\
& \begin{array}{ccc}
\begin{array}{c}
\text { Mixed throughout } \\
\text { the soil. }
\end{array} & \begin{array}{c}
\text { Top-dressed } 25 \text { days } \\
\text { after sowing. }
\end{array} & \begin{array}{c}
\text { Top-dressed directly } \\
\text { after sowing. }
\end{array}
\end{array}
\end{aligned}
$$

\begin{tabular}{|c|c|c|c|c|c|c|c|c|}
\hline grm. & $\begin{array}{c}\text { grm. } \\
\text { 4I.IO }\end{array}$ & $\begin{array}{l}\text { grm. } \\
6.20\end{array}$ & $\begin{array}{c}\text { grm. } \\
0.0\end{array}$ & $\begin{array}{l}\text { grm. } \\
0.0\end{array}$ & grm. & grm. & grm. & grm. \\
\hline $\begin{array}{l}4.0 \\
2.0\end{array}$ & 74.10 & $\begin{array}{l}11.60 \\
11.69\end{array}$ & 0.0 & 0.0 & - & - & - & - \\
\hline I.O & I 22.37 & 18.49 & 0.0 & 0.0 & -- & - & - & - \\
\hline 0.5 & I $43 \cdot 35$ & 22.03 & $65 \cdot 32$ & 11.92 & I 25.18 & $5.8 \mathrm{I}$ & I I 7.54 & I 4.93 \\
\hline $0 . \mathrm{I}$ & I 35.63 & 21.16 & II 8.84 & $21 \cdot 76$ & I 52.56 & 20.70 & II 4.85 & 19.60 \\
\hline 0.02 & 128.05 & $19 \cdot 70$ & $122 \cdot 3^{2}$ & $2 \mathrm{I} .88$ & I 55.83 & 20.59 & $160 \cdot 3^{6}$ & $2 \mathrm{I} \cdot 23$ \\
\hline Control & I 25.34 & $21 \cdot 33$ & I I 4.58 & 20.95 & I $59 \cdot 16$ & $21 \cdot 28$ & I $59 \cdot 16$ & $2 \mathrm{I} \cdot 28$ \\
\hline
\end{tabular}

$\mathrm{H}_{3} \mathrm{BO}_{3}$
per pot. $\quad$ Green Wt. DryWt. Green Wt. LryWt. GreenWt. DryWt. GreenWt. DryWt.

was any difference in the effect of the boric acid dressing when added immediately after sowing or when the plants were several inches high, both sets of plants being grown under strictly comparable conditions. ${ }^{2}$

Accordingly $0.5 \mathrm{grm}$., $\mathrm{O} . \mathrm{I}$ grm., and $0.02 \mathrm{grm} . \mathrm{H}_{3} \mathrm{BO}_{3}$ per pot was applied as a top-dressing-

(I) At the time of sowing.

(2) Seventeen days later.

In the first case, toxic effects such as retardation of germination and leaf injury were noticeable where $0.5 \mathrm{grm} . \mathrm{H}_{3} \mathrm{BO}_{3}$ had been applied, and even O.I grm. proved slightly unfavourable (Table VI). Where the dressing was

1 Pots containing only single plants were omitted in the mean.

${ }^{2}$ Infestation with aphis was successfully checked by spraying with $0.15-0.2$ per cent. nicotine in soap solution of I oz. per gallon. This had no apparent effect on experimental results. 


\section{Warington. - The Effect of Boric Acid and Borax on}

not applied until considerable growth had been made, $0.5 \mathrm{grm} . \mathrm{H}_{3} \mathrm{BO}_{3}$ per pot quickly caused signs of poisoning and a marked retardation in growth, the plants changing from a healthy green to a yellowish colour, and the leaves showing the typical brown margins. $0 \cdot \mathrm{I}$ grm. $\mathrm{H}_{3} \mathrm{BO}_{3}$ added at this stage, however, had only a very slight toxic effect.

At the close of the experiment there was no apparent difference between the plants treated with boric acid at the two stages of growth, though the dry and especially the green weights of the latter treated sets were slightly lower than those which received the dressing before germination (Table VI).

\section{General conclusions.}

(1) Applications of over I grm. of boric acid were injurious when mixed throughout the soil, though $0.5 \mathrm{grm}$. proved toxic if applied as a topdressing.

(2) In two instances a possible increase in the green weight was obtained with small quantities of $\mathrm{H}_{3} \mathrm{BO}_{3}$.

(3) Borax was possibly slightly less toxic than an equivalent amount of boric acid.

\section{TABLE VII.}

Mean Green and Dry Weights of Broad Beans grown in Pot Culture with Boric Acid and Borax containing equivalent Boron. (Quantities given in terms of $\mathrm{H}_{3} \mathrm{BO}_{3}$.)

Average of 6 pots. 2 plants per pot.

Top-dressed immediately after sowing, Mar. 18-June 16, I922. Boric Acid.

\begin{tabular}{|c|c|c|c|c|}
\hline \multirow{2}{*}{$\begin{array}{c}\mathrm{H}_{3} \mathrm{BO}_{3} \text { per } \\
\text { pot. }\end{array}$} & & \multicolumn{2}{|c|}{ 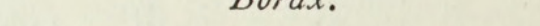 } \\
\hline & Green Weight. & Dry Weight. & Green Weight. & Dry Weight. \\
\hline$\underset{1.0}{\operatorname{grm} .}$ & $\begin{array}{l}\text { grm. } \\
76 \cdot 10\end{array}$ & $\underset{\mathrm{I} 2 \cdot 2 \mathrm{I}}{\operatorname{grm}}$ & $\begin{array}{l}\mathrm{grm} . \\
81.80\end{array}$ & $\begin{array}{l}\text { grm. } \\
\text { I } 2 \cdot 18\end{array}$ \\
\hline 0.5 & II 3.6 I & $18.7 \mathrm{I}$ & II 6.25 & $18 \cdot 31$ \\
\hline $0 . \mathrm{I}$ & I $33 \cdot 18$ & $2 \mathrm{I} .83$ & I 28.28 & 20.59 \\
\hline 0.02 & $134 \cdot 18$ & $2 \mathrm{I} .05$ & 129.59 & $22 \cdot 16$ \\
\hline Control & $133 \cdot 43$ & $2 \mathrm{I} \cdot 54$ & $133 \cdot 43$ & $2 \mathrm{I} \cdot 54$ \\
\hline
\end{tabular}

B. Barley.

The seed for these pot-culture experiments was the same as that used in the water-culture work; it was graded for each series, three plants being grown per pot.

a. The Effect of adding Various Quantities of Boric Acid to the Soil.

A wide range of concentrations of $\mathrm{H}_{3} \mathrm{BO}_{3}$ was tried : (a) Mixed throughout the soil ; $(b)$ applied as a top-dressing.

(a) Boric acid mixed throughout the soil $\left(22 \frac{1}{2} \mathrm{lb}\right.$.). From the outset 
barley was clearly more susceptible to boric acid injury than the broad bean, for the toxic effect was so severe where 4 grm. $\mathrm{H}_{3} \mathrm{BO}_{3}$ per pot was applied, that plants survived in two cases only. The injury was first evident in a strongly marked retardation in germination; the young shoots were yellow or even pink when they first appeared, but though they turned slightly green after about ten days, the majority of them failed to recover. The few survivors were extremely poor and scarcely tillered, and their leaves were badly spotted in a manner similar to that described for barley in waterculture experiments. Agulhon $(1(a))$ has stated that this peculiar reddish tinge is a typical symptom of boron-poisoning in cereals.

The crystalline substance deposited on the evaporation of the droplets of liquid which were exuded from the hydathode at the tip of the leaf-blade was collected from these chlorotic seedlings for several days in succession, the crystals from the control plants being collected separately at the same time. These two crystalline deposits were tested for boron by the following method, both a minute quantity of $\mathrm{H}_{3} \mathrm{BO}_{3}$ and distilled water being similarly tested as checks.

The crystals were dissolved in a drop of 95 per cent. alcohol; two or three drops of acetic acid and alcoholic turmeric were added, and with the further addition of a few c.c. of distilled water the whole was evaporated to dryness on a water-bath. The residue in the case of the crystals from the chlorotic seedlings was reddish-brown in colour, and turned blue-black on the addition of a drop of $\mathrm{NaOH}$, indicating the presence of boron. However, the residue from the crystals from the control plants remained yellowbrown in colour.

It would seem, therefore, that the boron added to the soil was taken up by the roots and passed up through the plant by the transpiration stream, as has been described by Free (19) in the case of Pelargonium; consequently the injury evident in these plants is most probably due to the presence of boric acid in the plant tissues.

Morse (26) has described a similar exudation of droplets from the leaf-margins of potatoes grown in pot culture in his experiments on borax in fertilizers. However, he makes no mention of testing such droplets for the presence of boron, though he detected it in the brown parts of the injured leaves. The grey deposit on the surface of the soil similar to that seen in the broad bean pot cultures was also noticed here.

An application of $2 \mathrm{grm} . \mathrm{H}_{3} \mathrm{BO}_{3}$ per pot was not nearly so injurious as $4 \mathrm{grm}$. (Table VIII), though germination was distinctly retarded and three of the fifteen plants died. Many of the young shoots were yellow or pink in colour, but they all turned green later and showed the typical brown flecking of the leaves. As fresh growth was made it rapidly became affected in the same way. All the plants tillered and came into ear: but the most striking feature of this set was their lateness in ripening, for when the 
controls and most of the other sets were fully mature, these plants were quite green. Voelcker (36) has described a similar retardation in his experiments on the action of boron on wheat and barley.

I grm. $\mathrm{H}_{3} \mathrm{BO}_{3}$ was also injurious, though the poisoning effects were less evident than where heavier dressings had been given (Table VIII); only slight injury in the early stages of growth was apparent in plants grown with $0.5 \mathrm{grm} . \mathrm{H}_{3} \mathrm{BO}_{3}$, and lower dressings produced no harmful effect at all ; in fact $0 . \mathrm{I}$ grm. seemed slightly beneficial, and a decided increase in the

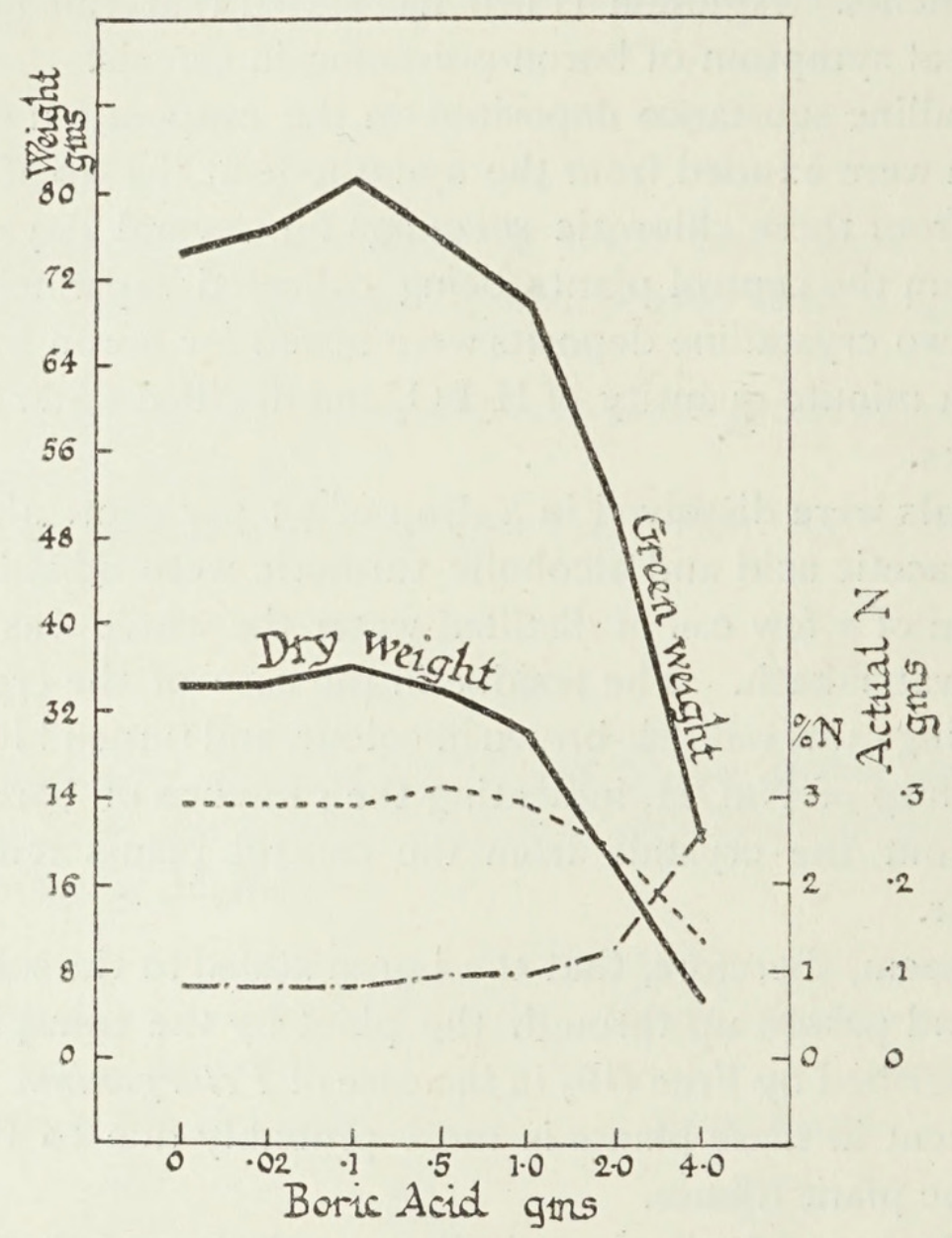

TEXT-FIG. 6. Barley grown in pot culture with various quantities of boric acid mixed throughout the soil. Feb. 24-July 8, I92 I (average of five pots): — Weight ; - - - - - - . per cent. Nitrogen; ...... Actual $\mathrm{N}$.

green weight was obtained, though the rise in the dry weight was only very slight (Table VIII and Text-fig. 6). These plants, however, matured slightly later than the controls and showed a few isolated cases of leaf spotting in the early stages. The untreated plants were in every way healthy and well grown, closely resembling the sets treated with the smallest quantities of boric acid in appearance and dry weight (Table VIII).

(b) Boric acid applied as a top-dressing fifteen days after sowing. Though barley suffered more injury than broad beans when the boric acid was mixed throughout the soil, in the top-dressing experiments the reverse occurred. Whereas even I grm. per pot completely killed all broad bean 
plants, barley was able to make some growth where a 2 grm. dressing had been applied (Table VIII). Difference in seasonal conditions cannot in any way be responsible for this result, as the corresponding experiments with beans and barley were set up on approximately the same dates. The duration of the experiments naturally differed owing to the longer growth period of barley, but since the injury was always most severe in the early stages of growth, this has probably little to do with the results. The toxic effects were exactly similar to those previously described for barley grown in pot culture.

A dressing of $4 \mathrm{grm} . \mathrm{H}_{3} \mathrm{BO}_{3}$ per pot completely killed all the plants, and though application of $2 \mathrm{grm}$. or I grm. per pot was not sufficient to prevent growth, yet the plants were severely injured (Table VIII), no ears being formed in the former sets, and the ripening off being noticeably retarded in both cases. Where 0.5 grm. $\mathrm{H}_{3} \mathrm{BO}_{3}$ was applied, this lateness in maturing was still seen and the leaves were badly spotted; however, a rise occurred in the green weight, though the dry weight was decidedly depressed (Table VIII). The lower dressings caused no injury, leaf spotting being evident in isolated cases only; in fact the effect was slightly beneficial, a distinct rise in the dry weight being obtained with the O.I grm. application (Table VIII), and both this set and the plants treated with $0.02 \mathrm{grm}$. appeared to the eye rather better than the controls, though similar in degree of maturity.

\section{Comparison between the Effect of Boric Acid and Borax in the Soil.}

The dressings of boric acid and borax were made immediately after sowing in this case, $\mathrm{I} \cdot \mathrm{O}$ boric acid being equivalent to $\mathrm{I} \cdot 54$ borax.

I grm. boric acid and the corresponding borax application caused a marked retardation in germination, and the shoots were of the characteristic yellow-pink colour; boron was again detected in the liquid exuded from these chlorotic seedlings.

Contrary to what occurred in the case of the broad bean, borax seemed more injurious than boric acid to barley, a result similar to that which Voelcker (36) obtained in I9I5. For example, fewer plants died in the set grown with $\mathrm{I}$ grm. of $\mathrm{H}_{3} \mathrm{BO}_{3}$, and the survivors made an earlier recovery and remained considerably better for some time than the corresponding borax-treated plants. However, at the close of the experiment there was little to choose between them, ears being formed in all cases and a similar retardation in maturing being apparent; both the green and dry weights also were very similar (Table IX). This may possibly be explained on the ground that the more soluble borax would permeate the soil more quickly, and therefore affect the plant more severely at first, but, since the quantity of boron in both cases was the same, the ultimate effect of the two compounds would be similar. The dark blue-green colour of these sets was 
suggestive of plants supplied with excessive nitrate, and the analogy was carried further in their lateness in maturing.

$0.5 \mathrm{grm} . \mathrm{H}_{3} \mathrm{BO}_{3}$ was also decidedly injurious, and the equivalent dressing of borax again proved more toxic, being in this case accompanied by a slight decrease in dry weight (Table IX). The injury was most apparent in quite the early stages of growth; the retardation in ripening was only very slight. Where $\mathrm{O} \cdot \mathrm{I}$ grm. $\mathrm{H}_{3} \mathrm{BO}_{3}$ or the equivalent quantity of borax was applied, toxic effects were rare, and at the close of the experiment these plants were slightly superior both to those receiving lower dressings and the controls; however, no stimulation was apparent from either the green or dry weight figures as in the previous experiments (Table IX). This discrepancy may be due to the seasonal conditions under which the experiments were respectively carried out, or possibly the beneficial effect may only be realized in the weight of the plant at a certain stage in its growth; in the one case, the plants may have been harvested before that stage had been reached, and further, such a stage may itself depend on seasonal conditions, being reached sooner in some years than in others.

\section{TABLE VIII.}

Mean Green and Dry Weights of Barley grown in Pot Culure. Average of 5 pots. 3 plants per pot. ${ }^{1}$

Mixed throughout soil.

Feb. 24-July 8, 192 I.

\begin{tabular}{|c|c|c|c|}
\hline $\begin{array}{c}\mathrm{II}_{3} \mathrm{BO}_{3} \text { per } \\
\text { pot. }\end{array}$ & Green Wt. & Dry Wt. & $\begin{array}{c}\text { \% Dry in } \\
\text { Green. }\end{array}$ \\
\hline $\begin{array}{l}\text { grm. } \\
4 \cdot 0\end{array}$ & $\begin{array}{l}\text { grm. } \\
20.15\end{array}$ & $\begin{array}{l}\text { grm. } \\
5 \cdot 10\end{array}$ & $25 \cdot 30$ \\
\hline 2.0 & $50 \cdot 44$ & I $8 \cdot 34$ & $36 \cdot 37$ \\
\hline I.O & $69 \cdot 70$ & 29.99 & 43.03 \\
\hline 0.5 & $75 \cdot 9^{2}$ & 33.86 & $44 \cdot 6 \mathrm{I}$ \\
\hline 0.1 & $8 I \cdot 26$ & 35.90 & $44 \cdot 18$ \\
\hline 0.02 & $76 \cdot 74$ & $34 \cdot 39$ & $44 \cdot 8$ I \\
\hline Control & 74.73 & $34^{\circ} 30$ & $45^{\circ} \cdot{ }^{\circ}$ \\
\hline
\end{tabular}

Top-dressed I 5 days after sowing. April I 5-Aug. 6, I92 I.

$\begin{array}{ccc}\text { Green Wt. } & \text { Dry Wt. } & \begin{array}{c}\text { Dry in } \\ \text { Green. }\end{array} \\ \text { grm. } & \text { grm. } & \\ 0.0 & 0.0 & - \\ \text { I } 3.89 & 5 \cdot 18 & 37 \cdot 29 \\ 26.68 & 9.99 & 37.44 \\ 41.56 & 16.00 & 38.50 \\ 39.83 & 26.16 & 65.67 \\ 32.35 & 22.07 & 68.21 \\ 34.29 & 21 \cdot 82 & 63.64\end{array}$

Agulhon $(1(a))$ has attributed the increase in the green weight value of plants grown with even slightly toxic doses of boric acid to an increase in water-holding capacity resulting from a state of over-mineralization, induced by the absorption of more than normal quantities of boron. Such an increase in water-content is shown up well by the values for the percentage of the dry in green weight in the various sets (Tables VIII and IX). In the case of the heavily treated plants which were so strikingly late in maturing, the value is very little more than half that of the controls, but the figure approximates to normal in those sets which show definite injury with a comparatively light dressing of boric acid.

\footnotetext{
1 Pots containing fewer than three plants were included in the mean, as they only occurred in heavily treated sets and were not caused by normal failure of germination.
} 


\section{General conclusions.}

I. $0 \mathrm{grm}$. or more $\mathrm{H}_{3} \mathrm{BO}_{3}$ per pot caused a depression in the dry weight, though $0.5 \mathrm{grm}$. was harmful if applied as a top-dressing. Possibly $\mathrm{O} . \mathrm{I}$ grm. was slightly beneficial, though lower dressings were ineffective.

2. Borax was slightly more toxic than an equivalent amount of boric acid.

The probable errors have been worked out in typical cases for both barley and broad beans grown in pot culture. With barley treated with a top-dressing of boric acid (Table VIII), the error for the green weight ranges from $\pm \mathrm{I} \cdot 5^{6}$ to \pm 0.24 , and for the dry weight from \pm 0.67 to $\pm \mathrm{c} \cdot 28$.

\section{TABLE IX.}

Mean Green and Dry Weights of Barley grown in Pot Culture with Boric Acid or Borax containing equivalent Boron. (Quantities given in terms of $\mathrm{H}_{3} \mathrm{BO}_{3}$.)

Average of 6 pots. 3 plants per pot. ${ }^{1}$

Top-dressed immediately after sozing. Mar. $15^{-A u g . .5}, 1922$.

Boric Acid. $\mathrm{H}_{3} \mathrm{BO}_{3}$ per Green Wt. Dry Wt.
pot.

$\begin{array}{lccc}\text { grm. } & \text { grm. } & \text { grm. } & \\ 1.0 & 34.63 & 13 \cdot 08 & 37.70 \\ \circ .5 & 35.01 & 18.65 & 53.20 \\ 0.1 & 33.65 & 21.49^{2} & 63.86 \\ \circ \cdot 02 & 30.48 & 21 \cdot 64 & 70.99 \\ \text { Control } & 35.64 & -2 & -\end{array}$

Borax.

Green Wt. Dry Wt. \% $\underset{\text { Green. }}{\text { Dry }}$

$\begin{array}{ccc}\text { grm. } & \text { grm. } & \text { grm. } \\ 34^{\cdot 68} & \mathrm{I} 3 \cdot 4^{8} & 38 \cdot 87 \\ 35^{\circ} \cdot 25 & \mathrm{I} 6 \cdot 42 & 46 \cdot 58 \\ 32 \cdot 7 \mathrm{I} & \mathbf{2 1} \cdot 35 & 65 \cdot 27 \\ 33 \cdot 37 & 22 \cdot 7 \mathrm{I} & 68 \cdot 00 \\ 35 \cdot 64 & -2 & -\end{array}$

TABLE X.

Nitrogen in Dry Matter. Broad Beans grown in Water Culture.

\begin{tabular}{|c|c|c|c|c|c|c|}
\hline $\begin{array}{c}\text { Concentration } \\
\text { of }\end{array}$ & \multicolumn{2}{|c|}{ Mar. Iо-May г } & \multicolumn{2}{|c|}{ April 28-June I3, } & \multicolumn{2}{|c|}{$\begin{array}{l}\text { Sept. } 3-\text { Oct. I } 7 \\
\text { I } 92 \mathrm{I} .\end{array}$} \\
\hline $\mathrm{H}_{3} \mathrm{BO}_{3}$. & $\% N$. & $\begin{array}{l}\text { Actual } N \text {. } \\
\text { grm. }\end{array}$ & $\% N$. & $\begin{array}{l}\text { Actual } N \text {. } \\
\text { grm. }\end{array}$ & $\% N$ & $\begin{array}{c}\text { Actual } N . \\
\text { grm. }\end{array}$ \\
\hline I $: 5,000$ & $4 \cdot 04$ & 0.22 & 2.94 & 0.20 & $4 \cdot 55$ & $0 \cdot 16$ \\
\hline I $: 25,000$ & $3 \cdot 19$ & $0 \cdot 3^{6}$ & $2 \cdot 6 \mathrm{I}$ & $0.2 \mathrm{I}$ & $4 \cdot 3^{I}$ & 0.23 \\
\hline I $: 50,000$ & 3.07 & $0.4 \mathrm{I}$ & $2 \cdot 6$ & 0.21 & $4 \cdot 4 \mathrm{I}$ & 0.22 \\
\hline I $: 100,000$ & $3 \cdot 3 \mathrm{I}$ & 0.38 & $2 \cdot 61$ & 0.22 & $4^{\circ 23}$ & 0.18 \\
\hline I : 500,000 & $3 \cdot 27$ & 0.36 & $2.6 \mathrm{I}$ & $0.2 \mathrm{I}$ & $4^{2} 24$ & 0.22 \\
\hline I $: 2,500,000$ & $3 \cdot 02$ & $0 \cdot 3^{8}$ & $2 \cdot 7^{2}$ & 0.23 & $4^{\circ}$ I I & 0.20 \\
\hline I $: 12,500,000$ & $3 \cdot 3 \mathrm{I}$ & $0 \cdot 38$ & 2.93 & 0.19 & $4: 30$ & 0.22 \\
\hline $1: 100,000,000$ & 3.08 & 0.27 & 3.42 & 0.18 & - & - \\
\hline Control & $3 \cdot 4 \mathrm{I}$ & $0 \cdot 3 \mathrm{I}$ & $3 \cdot 4^{8}$ & 0.15 & $4 \cdot 35$ & 0.11 \\
\hline
\end{tabular}

1 Pots containing fewer than three plants were included in the mean, as they only occurred in heavily treated sets and were not caused by normal failure of germination.

${ }^{2}$ Figures not available or mean of two pots only through accident. 
TABLE XI.

Nitrogen in Dry Matter. Broad Beans grown in Pot Culture.

\begin{tabular}{|c|c|c|c|c|c|c|c|}
\hline \multirow{3}{*}{$\begin{array}{l}\mathrm{H}_{3} \mathrm{BO}_{3} \text { per } \\
\text { pot. } \\
\text { grm. } \\
4 \cdot 0\end{array}$} & $\begin{array}{c}\text { Mixed throughout } \\
\text { the soil. } \\
\text { Mar. 4-May } 3 \mathrm{I}, \\
19^{2} \mathrm{I} \text {. }\end{array}$ & \multicolumn{2}{|c|}{$\begin{array}{l}\text { Top-dressed } 25 \text { days } \\
\text { after sowing. } \\
\text { April I5-June 29, } \\
\text { I92 I. }\end{array}$} & \multicolumn{4}{|c|}{$\begin{array}{l}\text { Top-dressed directly } \\
\text { after sowing. } \\
\text { Mar. I8-June I6, }\end{array}$} \\
\hline & $\begin{array}{c}\% N . \text { Actual } N . \\
\text { grm. }\end{array}$ & $\% N$. & $\begin{array}{l}\text { Actual } N \text {. } \\
\text { grm. }\end{array}$ & $\% N$ & $\begin{array}{l}\text { Actual } N . \\
\text { grm. }\end{array}$ & $\% N$ & $\begin{array}{l}\text { Actual } N . \\
\text { grm. }\end{array}$ \\
\hline & 3.59 & - & - & - & - & - & - \\
\hline 2.0 & $2 \cdot 95$ & - & - & - & - & - & - \\
\hline $1 \cdot 0$ & $2 \cdot 74$ & - & - & $3 \cdot 46$ & $0.4^{2}$ & $33^{2}$ & 0.40 \\
\hline 0.5 & 2.57 & 3.22 & $\begin{array}{l}0.3^{8} \\
0.55\end{array}$ & $\begin{array}{l}3 \cdot 28 \\
2.58\end{array}$ & $\begin{array}{l}0.01 \\
0.56\end{array}$ & $\begin{array}{l}3.13 \\
2.92\end{array}$ & $\begin{array}{l}0.57 \\
0.60\end{array}$ \\
\hline $\begin{array}{l}0.1 \\
0.02\end{array}$ & $\begin{array}{l}2.67 \\
2.50\end{array}$ & $\begin{array}{l}2.5 \mathrm{I} \\
2.62\end{array}$ & $\begin{array}{l}.55 \\
0.57\end{array}$ & $2 \cdot 77$ & 0.58 & $2 \cdot 95$ & $0.6_{5}$ \\
\hline Control & $\begin{array}{ll}2.59 & 0.55\end{array}$ & $2.6 \mathrm{I}$ & 0.55 & 3.00 & 0.65 & 3.00 & 0.65 \\
\hline
\end{tabular}

TABLE XII.

Nitrogen in Dry Matter. Barley grown in Water Culture.

Concentration

\begin{tabular}{|c|c|c|}
\hline of $\mathrm{H}_{3} \mathrm{BO}_{3}$. & $\% N$. & $\begin{array}{c}\text { Actual } N . \\
\text { grm. }\end{array}$ \\
\hline $1: 5,000$ & 3.87 & 0.06 \\
\hline $1: 25,000$ & $2 \cdot 80$ & 0.27 \\
\hline I $: 50,000$ & $2 \cdot 4^{2}$ & $0 \cdot 3^{6}$ \\
\hline I : 100,000 & $2 \cdot 36$ & $0.3^{6}$ \\
\hline I : 500,000 & $2 \cdot 09$ & 0.39 \\
\hline I : $2,500,000$ & $\mathbf{I} \cdot 78$ & 0.35 \\
\hline $1: 12,500,000$ & $I \cdot 54$ & 0.37 \\
\hline I : $100,000,000$ & $\mathrm{I} \cdot 88$ & 0.34 \\
\hline Control & $I \cdot 63$ & 0.35 \\
\hline
\end{tabular}

Mar. I-May I1, I922. Boric Acid. Borax. $\%$ N. Actual N. $\% N$. Actual $\Lambda$. grm. grm.

$\begin{array}{cccc}- & - & - & - \\ - & - & - & - \\ 4.26 & 0.23 & 4.25 & 0.21 \\ 3.70 & 0.24 & 3.39 & 0.23 \\ 3.54 & 0.24 & 2.93 & 0.23 \\ 3.34 & 0.22 & 3.02 & 0.25 \\ 3.10 & 0.27 & 2.99 & 0.25 \\ 3.01 & 0.26 & 2.60 & 0.25 \\ 2.59 & 0.25 & 2.59 & 0.24\end{array}$

TABLE XIII.

Nitrogen in Dry Matter. Barley grown in Pot Culture.

$\mathrm{H}_{3} \mathrm{BO}_{3}$ per
pot.
grm.
$4 \cdot 0$
$2 \cdot 0$
$\mathrm{I} \cdot 0$
$0 \cdot 5$
$0 \cdot \mathrm{I}$
$\mathrm{O} \cdot \mathrm{O} 2$
Control

Mixed throughout the soil. Feb. 24-July 8, 192 I. $\%$ N. Actual N. grm. $2 \cdot 52 \quad 0.13$ $\mathrm{I} \cdot 24 \quad 0.23$ $0.96 \quad 0.29$ $0.90 \quad 0.31$ $0.82 \quad 0.29$ $0.84 \quad 0.29$ $0.83 \quad 0.29$
Top-dressed I 5 days after sowing. April I5-Aug. 6, 1921. $\%$ N. Actual N.

$\begin{array}{ll} & \text { grm. } \\ - & - \\ 3 \cdot 37 & 0.18 \\ 2.87 & 0.29 \\ 2 \cdot 30 & 0.37 \\ \mathrm{I} \cdot 48 & 0.39 \\ \mathrm{I} \cdot 5 \mathrm{I} & 0.33 \\ \mathrm{I} \cdot 5 \mathrm{I} & 0.33\end{array}$

In the case of broad beans, however, the individual variation is very great, and the probable error for the series treated with boric acid mixed throughout the soil (Table VI) ranges from $\pm 7 \cdot 35$ to $\pm \mathrm{I} \cdot 92$ for the green 
weight, and for the dry weight from $\pm I \cdot 09$ to \pm 0.37 . The only conclusions that may be considered justifiable are therefore those relating to the boron injury; beneficial effects in pot culture, though apparent to the eye in some cases, must be regarded as questionable.

\section{Field Experiments.}

\section{A. Broad Beans.}

Three plots, each of area $\frac{1}{50}$ acre, were laid out in triplicate. All received a basal dressing of 3 cwt. superphosphate, I cwt. sulphate of potash, and $\frac{3}{4}$ cwt. sulphate of ammonia per acre. In addition, three plots received $20 \mathrm{lb} . \mathrm{H}_{3} \mathrm{BO}_{3}$, and three $8 \mathrm{lb} . \mathrm{H}_{3} \mathrm{BO}_{3}$ per acre ; the manures were applied as a top-dressing at the time of sowing. Owing to unfortunate weather conditions and a lack of uniformity in the seed sowing and the soil, the results regarding possible beneficial effects from the dressings were inconclusive, though no injury was apparent. However, in the three plots which were strictly comparable, a Io per cent. increase over the control was obtained in the yield of pods, harvested when green, from the plots receiving $8 \mathrm{lb}$. boric acid per acre.

B. Barley.

A similar series of plots were sown with barley. The mineral dressings were the same as for the broad bean plots, except that $1 \frac{1}{2} \mathrm{cwt}$. per acre of sulphate of ammonia was supplied. The manures were applied as a top-dressing just before sowing. No injurious or beneficial effects were evident from either of the dressings, and any differences in the yields from the various plots were well within the limits of experimental error.

\section{General Discussion.}

As boron is of such importance to the broad bean, the question naturally arises as to the part played by the element in the plant metabolism. It may be regarded on the one hand as an element similar in function to $\mathrm{C}, \mathrm{H}, \mathrm{O}, \mathrm{N}, \mathrm{S}, \mathrm{P}, \& \mathrm{c}$, , the only difference being the very small quantity of boron required; or, on the other hand, it may be classed as a catalytic agent not of itself directly useful, but able to aid some plant function in an indirect manner. Such a catalyst may even be essential for the normal functioning of the plant; for example, Bertrand $(4(b))$ has shown that the manganese in laccase is an oxygen carrier necessary for the functioning of the enzyme.

Agulhon (1 (a)) recognizes a class of elements which he terms ' particuliers'; these he considers are characteristic of certain groups of individuals or of life under certain conditions, and may be subdivided into two groups, (1) of nutritive, (2) of catalytic function; boron he regards as an example 
of the latter. But since a catalyst is essentially a substance not itself used up during the reaction upon which its presence depends, and since it is evident from the present work on the broad bean that the supply of boron must be continual in order to be effective, it would seem more probable that the action of the element is nutritive, and that it is in some way fixed by the plant and not in a state of circulation.

It has been shown by a number of workers on the subject, that certain of the Leguminosae readily respond to the action of boron compounds, yet even in this comparatively small group of plants a great difference in the degree of response is shown. Boron is apparently essential to the broad bean, and, as far as preliminary evidence goes, probably also to several other plants, such as the runner bean, dwarf bean, and crimson clover; while peas, wild white clover, and winter vetch appear to be more or less independent of its presence, though even in these cases some slight beneficial effect is evident from the addition of small quantities of $\mathrm{H}_{3} \mathrm{BO}_{3}$ to the nutrient solution.

The importance of the conditions under which the plant is growing on the reaction towards boron has been frequently seen during this investigation. For example, both the degree of toxicity of the same quantity of boric acid and the type of root developed in water culture by the untreated plants were found to vary with seasonal conditions, though the main results were independent of any such changes. High concentrations of boric acid were, for instance, considerably more injurious to broad beans grown in early spring or autumn than during the summer months, due probably to the fact that at such seasons growth was less vigorous and the plants less resistant to poisonous agents.

The roots of the control plants both in broad beans and crimson clover were less abnormal in appearance when grown in the late autumn than when set up earlier in the year, the stunted growth being hardly noticeable in the former series or at most only after a long time. In this case also, the slow rate of growth probably accounted for the delay in the appearance of the effects of boron deficiency, the roots being able to develop normally for a considerable time.

Whatever the function of boron, it is to some extent at least independent of the food supply, whether limited or abundant, for in Brenchley's $(11(a))$ work on the action of boric acid on peas and barley no renewal of the nutrient solution was made during the course of the experiment, yet the present results are in close agreement with this earlier work though the solutions were regularly renewed.

Nitrogen plays such a leading part in the nutrition of all plants that the effect of boron on the quantity of nitrogen absorbed is of importance. Consideration of Tables X-XIII and Text-figs. 2, 4, 5, 6 shows that the application of excessive amounts of boric acid was correlated with an 
increase in the percentage of nitrogen, though the actual nitrogen absorbed was either unaffected or considerably depressed. Cook and Wilson $(17(b))$ in field experiments found a higher percentage of $\mathrm{N}$ both in the straw and grain of wheat treated with boron than from the control plots; in fact it is a common experience that the presence of some injurious factor is accompanied by a rise in the percentage of nitrogen found in the plant. However, since the actual nitrogen absorbed is not increased by the presence of toxic agents, the rise in the percentage of nitrogen must be attributed mainly to a reduction in the output of dry matter of which the chief constituents are the carbohydrates, and not solely to the direct influence of the injurious factor on the intake of nitrogen. In the case of barley grown in water culture most of the concentrations of $\mathrm{H}_{3} \mathrm{BO}_{3}$ were toxic and the nitrogen percentage gradually rose as the quantity of boron was increased (Textfig. 4). With the broad bean the majority of the concentrations were beneficial and the percentage of nitrogen remained approximately constant, irrespective of the strength of boric acid supplied, but where the dose became toxic, i. e. 1 : 5,000, a rise was obtained as in the case of barley (Text-fig. 2).

However, the unhealthy condition due to a deficiency of boron, which was seen only with the broad bean in water culture, apparently had no effect on the percentage of nitrogen, although the actual amount was considerably lower than in the well-grown plants, in some cases falling even below that of the poisoned sets.

The right interpretation of the term 'stimulation' is still an open question, for it is equally difficult to define 'normal' growth. Peas in ordinary nutrient solution, for instance, apparently develop quite normally, but when the addition of a small quantity of boron causes a still better growth, the question arises as to whether the so-called 'normal' development was not really abnormal owing to the omission of some necessary element. And also, it is equally uncertain whether the plant might not be further improved by the addition of some other substance as yet undetected.

With broad beans the case is perhaps simpler, as it is clear that growth in the so-called 'complete' nutrient solution is abnormal; but here, again, it has not yet been shown whether other substances might not be able either to supply the same need or to still further benefit the plant.

The possibility of boric acid acting merely as an antiseptic agent has been shown by Agulhon $(1(a))$ to be quite unlikely, and in support of this, in the present experiments, moulds have occasionally developed on the roots of plants grown with toxic concentration of $\mathrm{H}_{3} \mathrm{BO}_{3}$. The acidifying action he also considered negligible, and this is confirmed by the fact that I : 5,000 boric acid is less acid than the normal nutrient solution used in this water-culture work, as determined by $\mathrm{pH}$ values. After analysing a large number of plants and plant organs for the presence of boron, 
Agulhon $(1(a))$ has put forward the idea that, as the element occurs in comparatively large quantities in the wood, it may be of especial importance in the formation of the vascular system. This view is supported by the fact that a disintegration of the vascular bundles takes place, proceeding from the apex downwards, in broad bean plants deprived of boron: this anatomical change is at present under investigation and will be described in a later paper.

Another noticeable feature in plants suffering from a deficiency of boron is that the injury is first apparent in the meristematic regions. Whereas death under normal conditions occurs first in the lower parts of the plant, 'dying off' progresses from the apex and travels downwards, so that the activities of boron appear to be closely connected with the healthy development of permanent from meristematic tissue.

The action of boron is presumably of a specific nature, since it appears to function in a different manner in different plants, possibly being in some cases an essential element, and in others of comparatively little importance.

The relationship of boron to plant life is somewhat suggestive of that between vitamines and animals, and in various ways the resemblance appears to be very close. The main lines of agreement are :

I. The comparatively small quantity of the substance required.

2. The unhealthy condition resulting from a deficiency of the substance.

3. The prevention of, or recovery from, the unhealthy condition by the addition of the substance.

4. The need for the supply of the substance to be maintained throughout life.

Accessory food factors or vitamines are utilized in small quantities quite out of proportion to the importance of their function, and similarly even $I: 2,5 \mathrm{co}, 000$ boric acid has been shown to be adequate for healthy growth of the broad bean. Vitamines are generally regarded as a class distinct from the better known animal food-stuffs, and it is conceivable that a similar category of accessory plant foods would afford a convenient means of classifying such substances as boron. A class of this nature was foreshadowed by Agulhon $(1(a))$ in his 'particuliers' elements, but he was not able to demonstrate a specific case where death resulted from the deficiency of such an element.

The function of boron in the life of the plant is still an unsettled question, though it seems more probable that its action is in some way nutritive rather than catalytic; similarly it is uncertain whether vitamines 'prove to be structural components of living tissues of which a supply is essential even though quantitatively unimportant, or whether (as it is equally possible) 
they are found to act rather as catalysts in certain normal processes of metabolism' (24).

But it must here be emphasized that no suggestion is made that boron is in any way analogous to a vitamine, but rather that their respective effects afford a striking parallel.

\section{SUMMARY.}

I. In water culture a continual supply of boric acid appears to be essential to the healthy growth of the broad bean plant, concentrations of I : I 2,500,000-I : $25,000 \mathrm{H}_{3} \mathrm{BO}_{3}$ being beneficial.

In its absence, death occurs in a characteristic manner, and the apex of the shoot becomes withered and blackened, though the addition of boric acid after these symptoms have set in results in a renewal of growth by means of new lateral shoots and roots. This type of dying never occurs in broad bean plants grown in pot culture, and it is concluded that sufficient boron is present, as a trace has been detected in the soils used.

2. The absence of boron does not cause death in barley, growth being healthy in ordinary culture solution.

3. Excess of boric acid is poisonous to the broad bean, injury being apparent with $\mathrm{I}: 5,000 \mathrm{H}_{3} \mathrm{BO}_{3}$ in water culture and with $0.5 \mathrm{grm}$. or over per $22 \frac{1}{2} \mathrm{lb}$. of soil in pot culture, according to the method of application. Smaller quantities added to the soil are either without effect or cause an increase in the green weight only.

4. Boric acid is more poisonous to barley than to the broad bean; in water culture a concentration of $\mathrm{I}: 2,500,000 \mathrm{H}_{3} \mathrm{BO}_{3}$ and in pot culture $\mathrm{I} .0 \mathrm{grm}$. or $0.5 \mathrm{grm}$. per $22 \frac{1}{2} \mathrm{lb}$ of soil is injurious, according to the method of application. Smaller quantities are either ineffective or slightly favourable, though the benefit is usually evident to the eye only and not shown in the dry weight.

5. Injury is marked by (1) retardation of germination; (2) first chlorosis and later brown markings of the leaves; the barley leaf becomes spotted, but that of the broad bean shows a band of brown along the margins ; (3) retardation in maturing in the case of barley in soil culture.

6. Preliminary experiments show that several other plants, and especially Phaseolus multiflorus and Trifolium incarnatum, appear to derive benefit from the addition of small quantities of boric acid to the nutrient solution, though rye behaves similarly to barley, and is apparently indifferent to low concentrations.

7. Boron is found to be present in considerable quantity in the dried shoots of broad bean plants grown in a nutrient solution containing no boron, and also in the seed. In garden-grown plants â larger proportion of boron was present in the pods than in either the stems or leaves. A trace 


\section{Warington.-The Effect of Boric Acid and Borax on}

was the most detected in the barley seed or in the dried shoots of untreated barley grown in water culture.

8. The function of boron in the case of the broad bean appears to be probably nutritive rather than catalytic, since a supply is required throughout the life of the plant. A parallel is drawn between the action of boron on plants and the vitamines on animal life.

In conclusion, I wish to express my thanks to Dr. W. E. Brenchley for her ready advice and helpful suggestions throughout this investigation. I am also indebted to Professor Biffen, Mr. Martin Sutton, and Captain Hunter for the supply of seeds used in the experimental work.

\section{Bibliography. ${ }^{1}$}

1. Agulhon, H. (a) (1910): Recherches sur la présence et le rôle du bore chez les végétaux. Thèse. Paris.

(b) (1910) : Emploi du bore comme engrais catalytique. Compt. Rend. Acad. Sci. Paris, 150 , No. 5, pp. 288-91.

(c) (1910): Accoutumance du maïs au bore. Ibid., I5I, No. 26, pp. I382-3.

(d) (1912): Emploi du bore comme engrais catalytique. Eighth Inter. Cong.

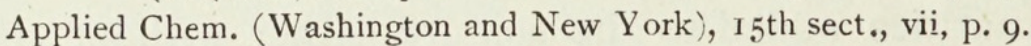

2 Andronescu, D. (1919): Germination and Further Development of the Embryo of Zea Mais separated from the Endosperm. Amer. Journ. Bot., vi, p. 443.

3. Archangeli, G. (1885): Sopra l'azione dell' acido borico sul germogliamento dei semi. Processi verbali Soc. Toscana Sci. Nat., Pisa, v, p. 25.

4. Bertrand, G. (a) (1911): Les engrais catalytiques et la culture de la betterave. Rev. Sci., Paris, 49, No. 22, p. 673 .

(b) (1912): Sur le rôle des infiniment petits produits chimiques en agriculture. Conf. $8^{e}$ Congrès Inter. Chim. App. (New York, 1912); also in Rev. Sci., Paris, Jan. I8, I9I3.

5. Bertrand, G., and Thomas, P.: Practical Biological Chemistry, p. 16. G. Bell and Sons.

6. Blair, A. W. (1920): Borax Fertilizer Experiments, showing Striking Results. Ref. in Exp Sta. Rec., vol. xliv, no. 5 , p. 42 .

7. Blair, A. W., and Brown, B. E. (1921): The Influence of Fertilizers containing Borax on the Yield of Potatoes and Corn. Soil Science, vol. xi, p. 369 .

8. Blackwell, C. P., and Collins, C. H. (1920) : 'I'rona Potash; a Progress Report. S. Carolina Agr. Exp. Sta. Bull., 202.

9. Bonnet, C. (1754): Recherches sur l'usage des feuilles dans les plantes et sur quelques autres sujets relatifs à l'histoire de la végétation. Göttingen and Leyden.

10. BreckenRIDge, J. E. (1921): Boron in Relation to the Fertilizer Industry. Journ. Indus. and Engin. Chem., I3, No. 4, pp. 324-5.

11. Brenchley, W. E. (a) (1914): On the Action of certain Compounds of Zinc, Arsenic, and Boron on the Growth of Plants. Ann. Bot., vol. xxviii, pp 28 8 -30r. Press.

(b) (1914): Inorganic Plant Poisons and Stimulants. Cambridge Univ.

1 A few papers are included which are not referred to in the text. 
12. Brows, B. E. (1922) Effect of Borax in Fertilizers on Growth and Yield of Potatoes. U.S. Dept. Agric. Bull., $99^{8}$, p. 8.

13. BRuno, A. (1920): La toxicité du borax pour les végétaux. Ann. de la Sci. Agron., xxxvii.

14 Conner, S. D. (1918): The Injurious Effect of Borax on Corn. Proc. Ind. Acad. Sci., pp. I95-9.

15. Conner, S. D., and Fergus, E. N. (1920): Borax in Fertilisers. Indiana Sta. Bull., 239, pp. $3^{-1} 5$.

16. Cook, F. C. (1916) : Boron, its Absorption and Distribution in Plants and its Effect on Growth. U.S. Dept. Agric Journ. Agr. Res., 5, No. I9, p. 877 .

17. Cook, F. C., and Wilson, J. B. (a) (1917): Effect of Three Annual Applications of Boron on Wheat. Ibid., Iо, No. I2, p. 59 I.

(b) (1918): Boron; its Effect on Crops and its Distribution in Plants and Soil in Different Parts of the U.S.A. Ibid., I3, No. 9, p. 45 r.

18. Duggar, B. M. (1922): The Nutritive Value of the Food Reserve in the Cotyledons. Ann. Miss. Bot. Garden, vol. vii, No. 4, p. 29 I.

19. Free, E. E. (1917) : Symptoms of Poisoning by certain Elements in Pelargonium and other Plants. Johns Hopkins Univ. Circ., N.S., No. 3, pp. 195-8.

20. Haselhoff, E. (1913): Über die Einwirkung von Borverbindungen auf das Pflanzenwachstum. Landsw. Vers.-Stat., 79-80, pp. 399-429.

21. Heckle, E. (1875): De l'action de quelques composés sur la germination des graines (bromure de camphre, borate, silicate et arséniate de soude). Compt. Rend., 80, pp. II 70-2.

22. Mason, T. G. (1922): Growth and Abscission in Sea Island Cotton. Ann. Bot., xxxvi, p. 457. 23. Mazé, P. (a) (1916): Determination of Elements necessary to the Development of Maize. Compt. Rend., i6o, No. 6, pp. 2 III-I4.

(b) (1919) : Recherche d'une solution purement minérale capable d'assurer l'évolution cơmplète du maïs cultivé à l'abri des microbes. Ann. Inst. Pasteur, 33, p. I39.

24. Medical Research Committee (1919): Report on the Present State of Knowledge concerning Accessory Food Factors (Vitamines).

25. Morel, J. (1892): Action de l'acide borique sur la germination. Compt. Rend., II 4, pp. I3I-3. 26. Morse, W. J. (1920): Some Observations upon the Effect of Borax in Fertilizers. Maine Agr. Exp. Sta. Bull., 288, pp. 89-I 20.

27. Neller, J. R., and Morse, W. J.(1921): Effect upon the Growth of Potatoes, Corn, and Beans resulting from the Addition of Borax to the Fertilizers used. Soil Science, vol xii.

28. Peligot, E. (1896): De l'action que l'acide borique et les borates exercent sur les végétaux. Compt. Rend., 83 , pp. 686-8.

29. Pellet, H. (1913): The so-called 'Catalytic' Action of Manganese and Boron Compounds on the Cultivation of Sugar-beet. Bull. Assoc. Chim. Sucr. et Distill., 3I, No. 6, pp. 4I9-24.

30. Plummer, J. K., and Wolff, F. A. (1920): Injury to Crops by Borax. N. Carolina Dept. Agr. Bull., 4I, No. I5, p. 20.

31. Proulx, E. G., Deemer, R. B., Bitler, R. O., Thornton, S. F., Ford, O. W., Roberts, O. S. (1918): Injury to Corn causcd by Borax in Fertilizers. Indiana Agr. Exp. Sta. Bull., 21 5 , pp. I6-18.

32. Sachs, J. (1859): Physiologische Untersuchung über die Keimung der Schminkbohne (Phaseolus multiflorus). Sitzungsber. Kaiser. Akad. Wiss. Wien, Math.-Naturw. Kl., 37, p. 57.

33. Schreiner, O., Brown, B. E., Skinner, J. J., Shapovalov, M. (1920): Crop Injury by Borax in Fertilizers. U.S. Dept. Agr. Dept. Circ., 84.

34. Sherwin, M. E. (1920): Effect of Fertilizers on Germination and Seedling Growth of Corn and Cotton. Journ. Elisha Mitchell Sci. Soc., 36, p. I6.

35. Vinson, A. E., and Catrin, C. N. (1916): Plant Stimulation with Non-essential Elements. Arizona Sta. Rept., I9 6 , p. 300.

36. Voelcker, J. A. (1915): The Influence of Boron Compounds on Wheat and Barley. Woburn Exp. Sta. Rept., I9I5, pp. 30-7.

37. Wittstein, A., and Apoiger, F. (1857): Entdeckung der Borsäure im Pflanienreiche. Ann. der Chemie und Pharmacie (Liebig), I०3, pp. 362-4. 


\section{EXPLANATION OF PLATE XIII.}

Illustrating Miss Warington's paper on the Effect of Boric Acid and Borax on the Broad Bean and certain other Plants.

All plants have been grown in water culture in nutrient solution.

Photograph I. Typical root of broad bean grown without boric acid.

Photograph 2. Typical root of broad bean grown with a small quantity of boric acid.

Photograph 3. Broad bean shoot showing new growth (on left) subsequent to the addition of boric acid after the characteristic death of the main axis (on right).

Photograph 4. Broad bean showing the comparative size of shoots before and after the addition of boric acid. The small main axis (on left) was the only shoot before treatment with boric acid.

Photograph 5. Broad beans grown with various concentrations of boric acid; (left to right) I : 5,000 ; I : 50,000 ; I : 100,000; I : 500,000; control with no boric acid.

Photograph 6. Addition of boric acid to broad beans after increasing periods before treatment; (left to right) 0 , 10, 20-60 days.

Photograph 7. Removal of boric acid from broad beans after increasing periods of treatment; (left to right) 0 , I0, 20-70 days.

Photograph 8. Barley grown with various concentrations of borax; (left to right) control with no borax; I : 100,000,000 increasing to $\mathrm{I}: 50,000$ (terms given as boric acid).

Photograph 9. Comparison between barley grown with boric acid (I : I 2,500,000) and borax (on right) containing equivalent boron.

Photograph 10. Preliminary result of the effect of boric acid on the runner bean. Control with no boric acid (on left); I : 2,500,000 (on right).

NOTE. - Since this paper went to press attention has been drawn to a paper by Addoms (Amer. Journ. Bot., x, 1923 ) in which the author shows that a short, stubby, branched root system (as described above on p. 634) is associated with high concentrations of potassium di-hydrogen phosphate and the consequent high hydrogen-ion concentration. However, although the nutritive solution used in these experiments contained a relatively large amount of this salt, yet it is not entirely responsible for the distinctive root growth here described, as a very similar type of root system has since been obtained when part of the phosphate was supplied in the form of the mono-hydrogen salt, thereby considerably reducing the hydrogen-ion concentration. 
Annals of Botany,
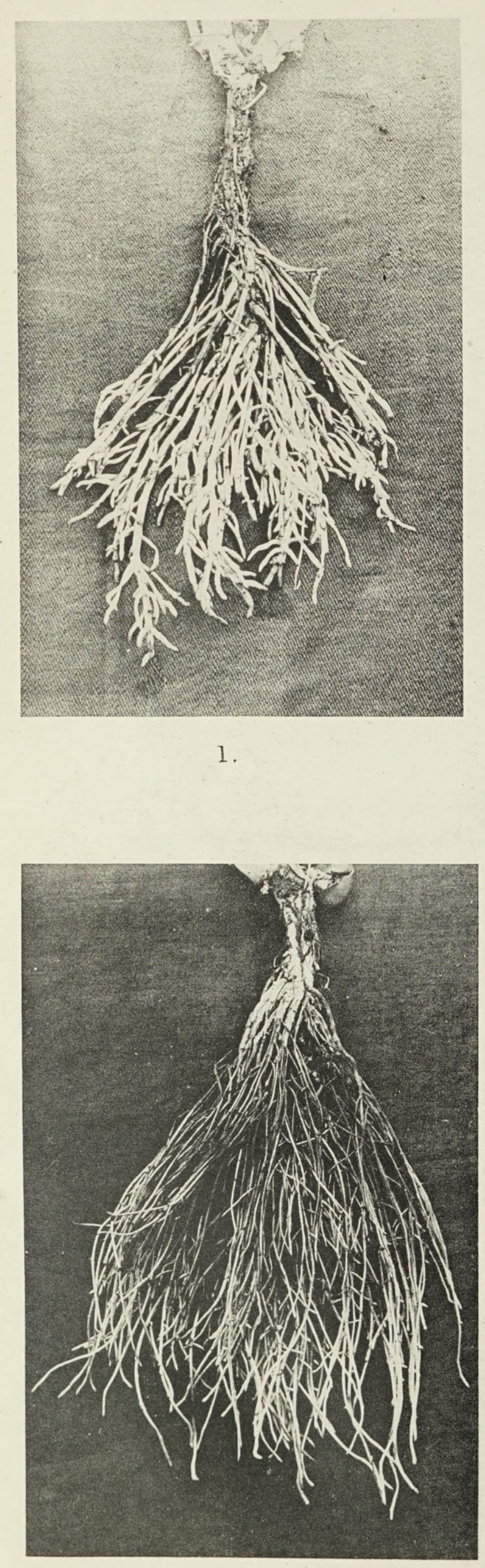

2.

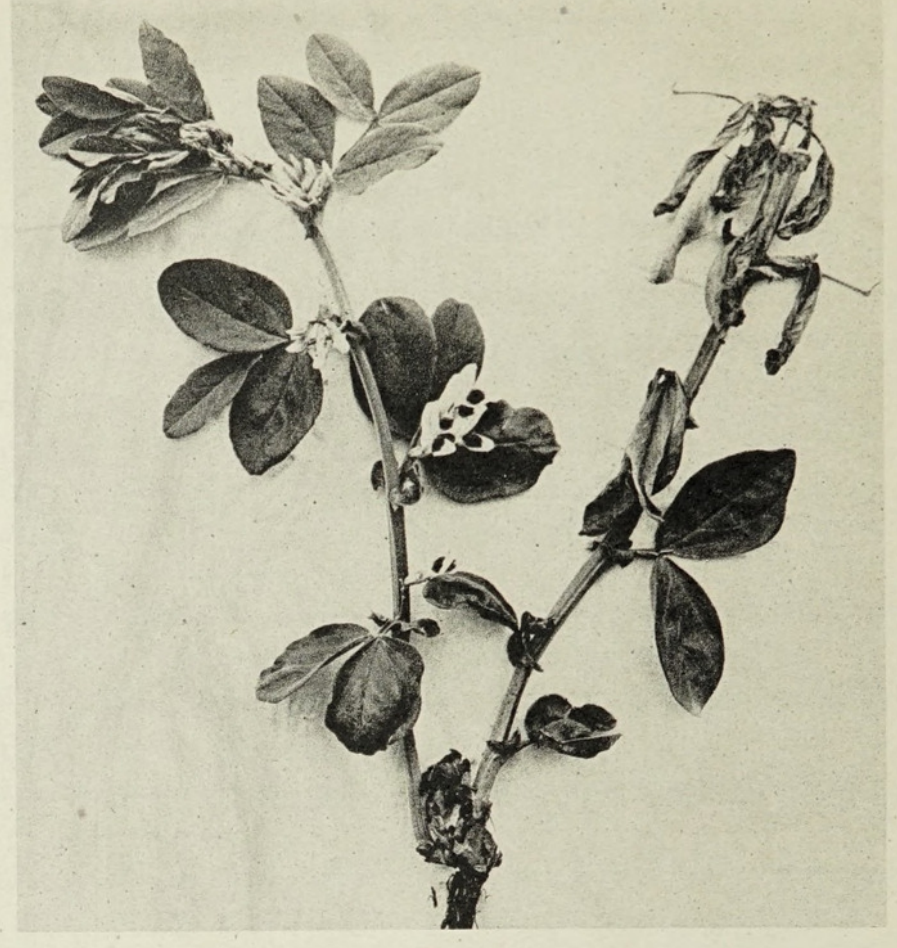

3.

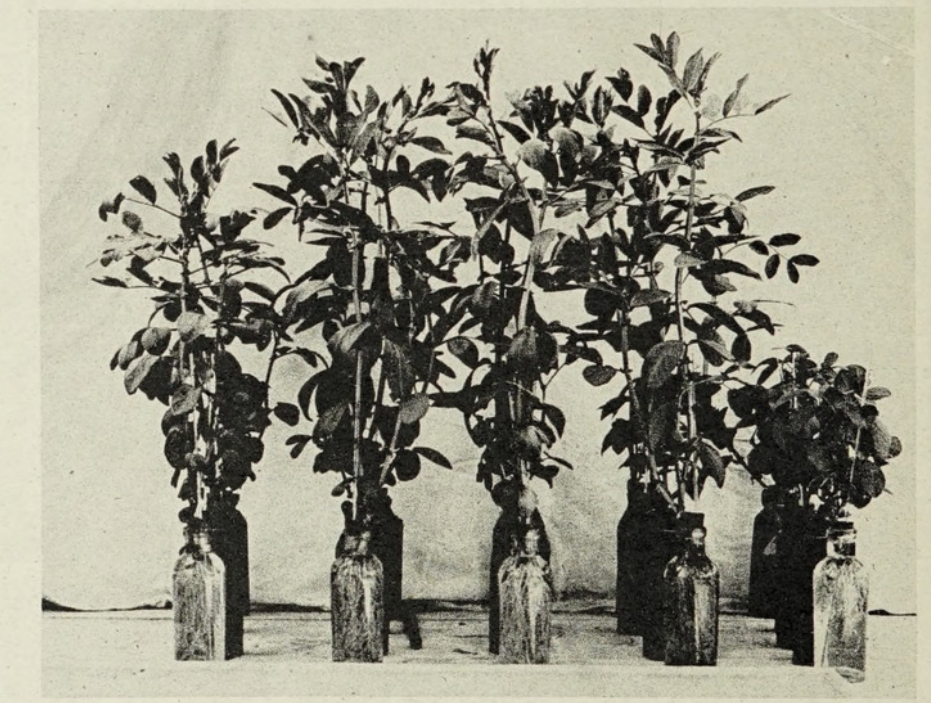

5.
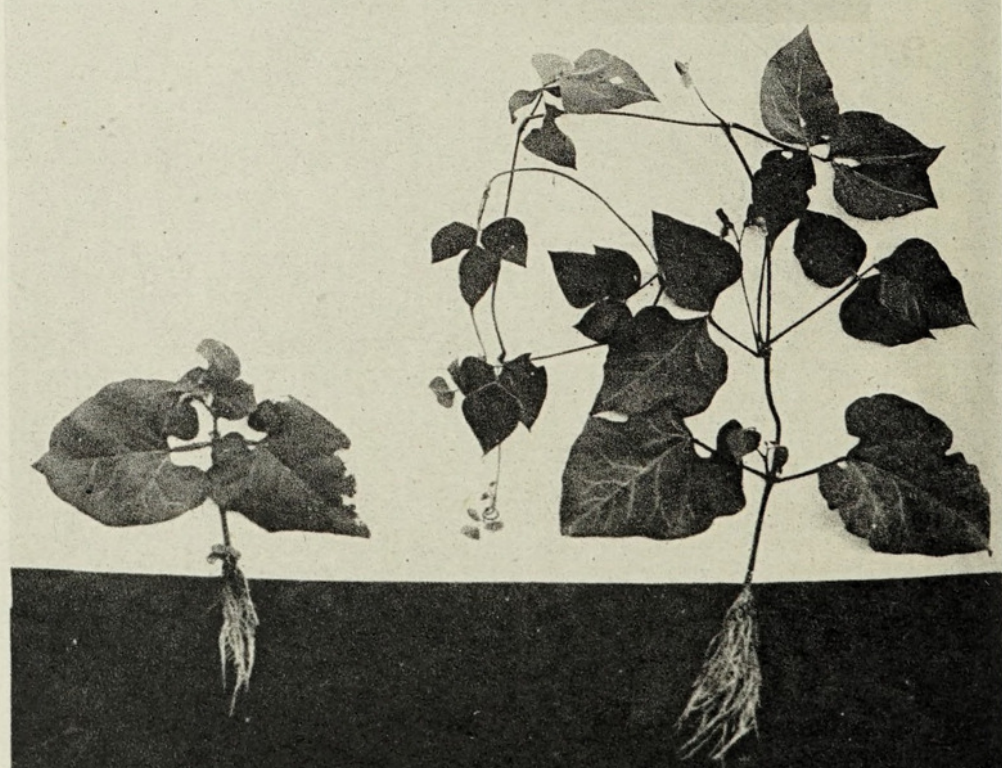

WARINGTON- EFFECT OF BORIC ACID. 


\section{$2 \mathrm{BHL}$ Biodiversity Heritage Library}

Warington, Katherine. 1923. "The effect of boric acid and borax on the broad bean and certain other plants." Annals of botany 37, 629-672. https://doi.org/10.1093/oxfordjournals.aob.a089871.

View This Item Online: https://www.biodiversitylibrary.org/item/270686

DOI: https://doi.org/10.1093/oxfordjournals.aob.a089871

Permalink: https://www.biodiversitylibrary.org/partpdf/319107

\section{Holding Institution}

New York Botanical Garden, LuEsther T. Mertz Library

\section{Sponsored by}

BHL-SIL-FEDLINK

\section{Copyright \& Reuse}

Copyright Status: Public domain. The BHL considers that this work is no longer under copyright protection.

This document was created from content at the Biodiversity Heritage Library, the world's largest open access digital library for biodiversity literature and archives. Visit BHL at https://www.biodiversitylibrary.org. 